\title{
A CENTRIFUGE MODEL STUDY ON PILE GROUP RESPONSE TO ADJACENT TUNNELING IN SAND
}

\author{
Ittichai BOONSIRI ${ }^{1}$ and Jiro TAKEMURA ${ }^{2}$ \\ ${ }^{1}$ Member of JSCE, Ph.D. candidate, Dept. of Civil Eng., Tokyo Institute of Technology \\ (2-12-1, O-okayama, Meguro-ku, Tokyo 152-8552, Japan) \\ E-mail: Boonsiri.i.aa@m.titech.ac.jp, ittichaiboon88@gmail.com \\ ${ }^{2}$ Member of JSCE, Professor, Dept. of Civil Eng., Tokyo Institute of Technology \\ (2-12-1, O-okayama, Meguro-ku, Tokyo 152-8552, Japan) \\ E-mail: jtakemur@cv.titech.ac.jp
}

\begin{abstract}
In urban areas, there are inevitable interactions between existing structures and new constructions such as tunneling. A series of centrifuge model tests has been carried out to study the effects of tunnelling-induced soil movements on the adjacent pile group in sand. The tunneling process was simulated by reducing the diameter of the model tunnel for various ground loss values in $100 \mathrm{~g}$ centrifugal acceleration. The tunneling machine is a mechanical type that can reduce diameter in co-axial direction to create a clear boundary condition. Two model pile groups consisting of four piles each with different lengths were embedded in dry sand at either side of the tunnel. The effects of horizontal distance between the pile and tunnel center $\left(X_{p}\right)$, relative pile tip position to the tunnel center $\left(Z_{p e}\right)$, vertical loads on the pile groups, and cover depth ratio $(C / D)$ were investigated in this study. Zones of influence were applied to investigate the area of large soil movements with the adjacent pile group. For small ground loss ratio $\left(\Delta V / V_{0}\right)$, the pile group movements increased almost proportionally to $\Delta V / V_{0}$. While for the large $\Delta V / V_{0}$ over $3 \%$, the pile movement increment gradually decreased with $\Delta V / V_{0}$, except for the pile group with the front pile resting in the large displacement zone, of which movement still proportionally increased with $\Delta V / V_{0}$. The effect of $X_{p}$ and $Z_{p e}$ on the pile cap movement could be reasonably combined with the relative depth from the boundary of the less-movement zone to the pile length. Relative pile depth in the less displacement zone to the pile length and the horizontal position are the critical controlling factors of the profiles of pile bending moment and axial force.
\end{abstract}

Key Words : pile group, tunnelling-induced soil movements, sand, centrifuge model

\section{INTRODUCTION}

In urban areas, many new tunnels have been planned to be constructed in congested underground space. The adverse effects of tunnel construction on the present structures should be minimized, especially on pile foundations. Many researchers have investigated the behavior of complex mechanism between pile-soil-tunnel interactions using various methods, such as empirical equations, numerical and physical modelings. Although the numerical studies have produced variable interesting results, there are still some uncertainties and validation of proposed construction methods is required. Furthermore there are many factors that might affect the behavior, such as, types of soil, types of tunneling and imposed soil movement or ground loss by tunneling, tunnel depth, types of piles (single and group), depth and location of piles, pile bearing capacity, load supported by the piles. In addition, the shape of sub soil settlement trough in the green field is a function of depth influenced by the magnitude of ground loss ratio $\left(\Delta V / V_{0}: \Delta V\right.$ : the volume of tunnel contraction per unit length, $V_{0}$ : the volume of the tunnel) and cover and depth ratio $(C / D)^{1)}$.

During the tunnel boring process, it is difficult to control the volume of soil removal, leading to changes in the stress state and the movement of the soil. The study on the effects of these changes on the adjacent pile foundation is essential when a bored tunnel is constructed in an urban area with many pile foundations. There are few case histories available about the behavior of piles subjected to tunnel excavation $^{2), 3)}$. The interaction between soil-pile-tunnel is more complicated to model with numerical calculation, especially in three-dimensional problem ${ }^{4)}$. 
Therefore, the effects of tunneling-induced soil movements on the pile foundations have not been well understood.

The tunneling effect on pile with $1 \mathrm{~g}$ physical modeling has been conducted by many researchers. ${ }^{5), 6)}$ They found that the existing pile foundation will change the shape of settlement trough due to the concentration of surface settlement around the foundation. Sung et al. ${ }^{7}, 2006$ found that the magnitude of differential settlement and rotation are large when only the front pile locates in the large deformation region. On the contrary, the magnitude of differential settlement and rotation become small when all piles locate in the large deformation region. In addition, the end bearing reduction and of front pile in the region of large soil deformation could be observed.

Physical modeling using centrifuge technology has become popular in studying these kinds of problems because it can reproduce ground stress of full-scale prototype within a small-scale model. The centrifuge model tests have proved to be valuable in studying deformation and collapse of soil model in a laboratory ${ }^{8)}$. Therefore, the study of interaction between pile foundation and tunnel by centrifuge model has become popular.

From centrifuge tests on single piles, Lee and Chiang ${ }^{9)}$ revealed that the relative depth of tunnel to the single pile had a significant influence on the bending moment, while the axial force along the single pile was affected by both the relative depth and working load. For the tunneling at the depth near the pile end, the settlement rapidly increased with a significant reduction of end bearing resistance due to the ground loss, which was more marked when the ratio of pile - tunnel center distance to the tunnel radius $\left(X_{p} / R\right)$ was less than 1.5. From centrifuge tests of pile group and single pile with a constant $X_{p}\left(X_{p}=1.83\right)$ and a constant vertical load, Loganathan et al. ${ }^{10)}$ showed that the lateral deformation and moment became critical when the depth of pile end was located near the tunnel center. The results were similar for single pile and a pile in a group at an identical distance from the tunnel. In addition, the induced axial forces were critical for the piles shallower than the tunnel center.

The above-mentioned researches provided important information about the mechanical behavior of piles subjected to tunneling-induced soil movements. However, there are still unclear responses of piles, especially for the pile group, such as the effect of various working loads and the distance between the pile and the tunnel.
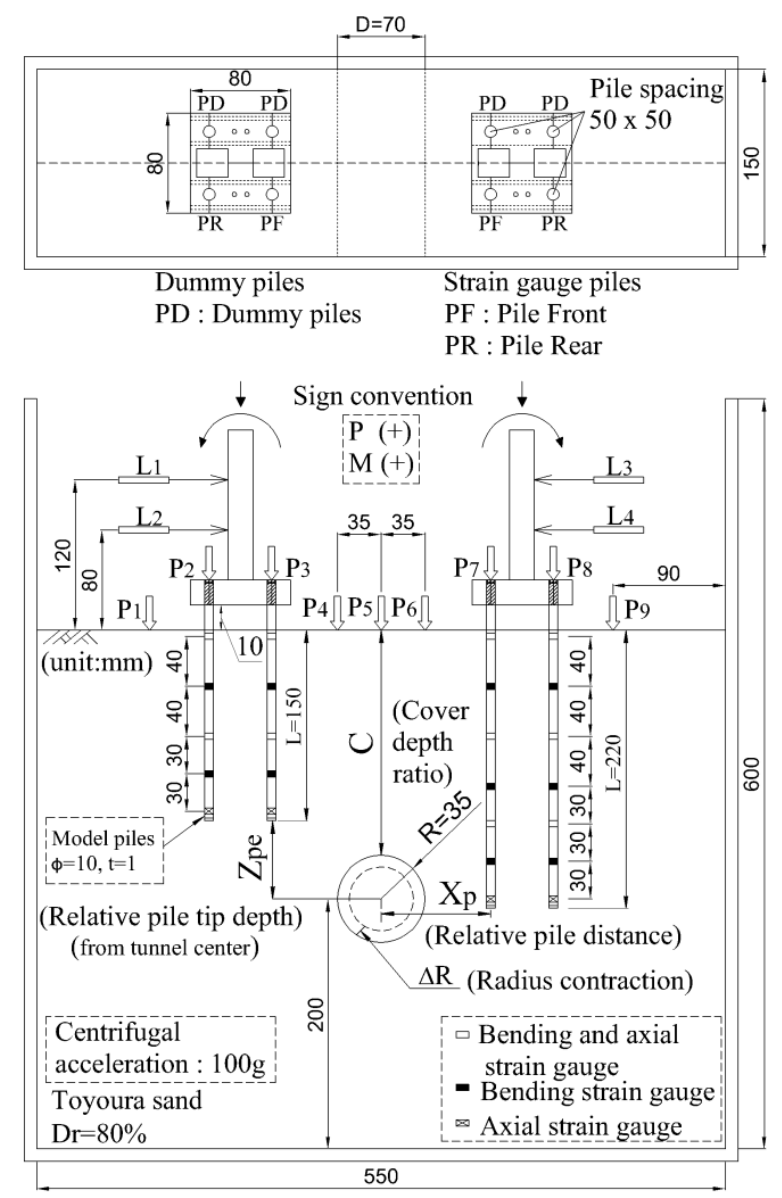

Laser displacement transducer

$\mathrm{L} 1+\mathrm{L} 2+\mathrm{L} 3+\mathrm{L} 4$ : pile inclination and lateral displacement

If. Potentiometers

$\mathrm{P} 2+\mathrm{P} 3+\mathrm{P} 7+\mathrm{P} 8 \quad$ : Pile cap settlement

$\mathrm{P} 1+\mathrm{P} 4+\mathrm{P} 5+\mathrm{P} 6+\mathrm{P} 9$ : Ground surface settlement

Fig.1 Test set up and instrumentation.

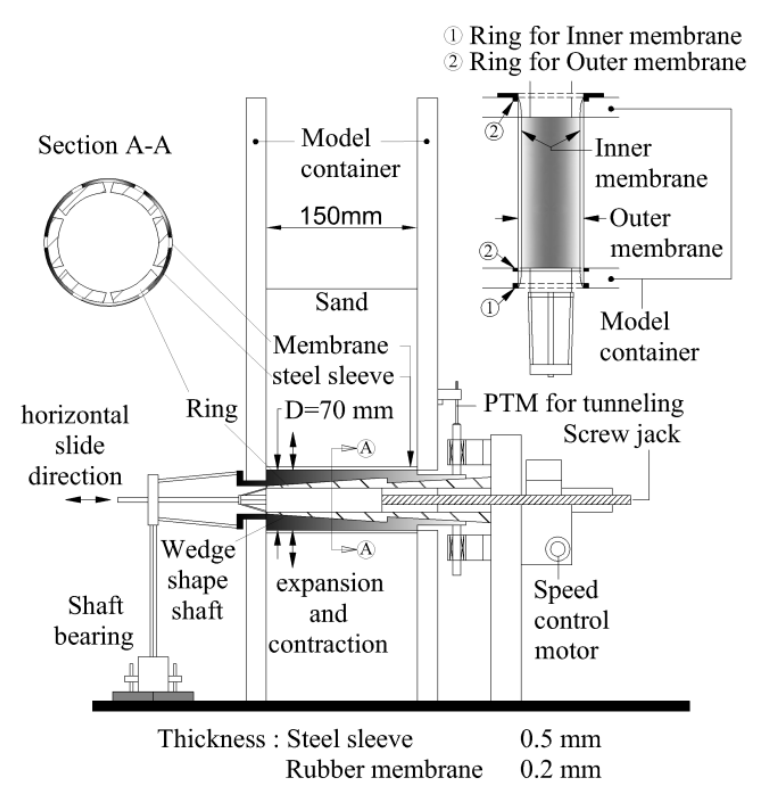

Fig.2 Tunnel machine. 
Table 1 Test conditions and results.

\begin{tabular}{|c|c|c|c|c|c|c|c|c|c|c|c|c|}
\hline \multirow{3}{*}{$\begin{array}{c}\text { Test } \\
\text { Series }\end{array}$} & \multirow{3}{*}{$\begin{array}{l}\text { Test } \\
\text { Code }\end{array}$} & \multirow{3}{*}{$\begin{array}{l}D_{r} \\
(\%)\end{array}$} & \multirow{3}{*}{$C / D$} & \multirow{3}{*}{$\begin{array}{c}X_{p} / R \\
\text { @ } \\
\text { Front } \\
\text { pile }\end{array}$} & \multicolumn{3}{|c|}{ Short pile } & \multicolumn{3}{|c|}{ Long pile } & \multirow{2}{*}{\multicolumn{2}{|c|}{$\frac{x_{i} / R}{\Delta V / V_{0}}$}} \\
\hline & & & & & \multirow[t]{2}{*}{$Z_{p e} / R$} & \multirow{2}{*}{$\begin{array}{c}\text { Loading } \\
\text { mass* } \\
(\mathrm{kg}) \\
\end{array}$} & \multirow{2}{*}{\begin{tabular}{|c|} 
Load per \\
pile** \\
$(\mathrm{kN})$
\end{tabular}} & \multirow{2}{*}{$Z_{p e} / R$} & \multirow{2}{*}{$\begin{array}{c}\text { Londing } \\
\text { Mass* } \\
(\mathrm{kg})\end{array}$} & \multirow{2}{*}{$\begin{array}{c}\text { Load per } \\
\text { pile** } \\
(\mathrm{kN})\end{array}$} & & \\
\hline & & & & & & & & & & & $2 \%$ & $15 \%$ \\
\hline \multirow{2}{*}{ A } & Case0-D & \multirow{13}{*}{80} & 2.5 & \multirow{2}{*}{\multicolumn{7}{|c|}{ Without pile groups installation }} & 2.6 & 2.2 \\
\hline & Case0-S & & 1.5 & & & & & & & & 1.8 & 1.5 \\
\hline \multirow{3}{*}{$\mathrm{B}(1)$} & Case2.0-DH & & 2.5 & 2.0 & -1.72 & 1.04 & 2600 & 0.28 & 2.03 & 5070 & 3.3 & 2.6 \\
\hline & Case2.5-DH & & 2.5 & 2.5 & -1.72 & 1.04 & 2600 & 0.28 & 2.03 & 5070 & 3.2 & 2.5 \\
\hline & Case3.0-DH & & 2.5 & 3.0 & -1.72 & 1.04 & 2600 & 0.28 & 2.03 & 5070 & 2.9 & 2.2 \\
\hline \multirow{4}{*}{$\mathrm{B}(2)$} & Case1.5-DL & & 2.5 & 1.5 & -1.72 & 0.76 & 1900 & 0.28 & 1.04 & 2600 & 3.1 & 2.5 \\
\hline & Case2.0-DL & & 2.5 & 2.0 & -1.72 & 0.76 & 1900 & 0.28 & 1.04 & 2600 & 3.0 & 2.4 \\
\hline & Case2.5-DL & & 2.5 & 2.5 & -1.72 & 0.76 & 1900 & 0.28 & 1.04 & 2600 & 2.9 & 2.4 \\
\hline & Case3.0-DL & & 2.5 & 3.0 & -1.72 & 0.76 & 1900 & 0.28 & 1.04 & 2600 & 2.7 & 2.3 \\
\hline \multirow{4}{*}{$\mathrm{C}$} & Case1.5-SL & & 1.5 & 1.5 & 0.28 & 0.76 & 1900 & 2.28 & 1.04 & 2600 & 2.1 & 1.7 \\
\hline & Case2.0-SL & & 1.5 & 2.0 & 0.28 & 0.76 & 1900 & 2.28 & 1.04 & 2600 & 2.0 & 1.7 \\
\hline & Case2.5-SL & & 1.5 & 2.5 & 0.28 & 0.76 & 1900 & 2.28 & 1.04 & 2600 & 1.9 & 1.6 \\
\hline & Case3.0-SL & & 1.5 & 3.0 & 0.28 & 0.76 & 1900 & 2.28 & 1.04 & 2600 & 1.8 & 1.6 \\
\hline
\end{tabular}

$*$ : model, $* *$ : prototype for $100 \mathrm{~g}$

In this study, a series of centrifuge model tests were carried out to investigate pile-soil-tunnel interaction of piles group in dry sand. The pile group movements, the induced bending moment and the load transfer mechanism were studied to enhance the knowledge of piles group subjected to the new tunnel construction.

\section{TEST SETUP}

The tunneling tests with piles were conducted by using Tokyo Tech Mark III centrifuge ${ }^{11)}$. The models were prepared in aluminum-made container with transparent perspex window of $550 \mathrm{~mm}$ in length, $150 \mathrm{~mm}$ in width, and $600 \mathrm{~mm}$ in height, to produce a two-dimensional plane strain deformation under $100 \mathrm{~g}$ as shown in Fig. 1. A digital camera was installed in front of the container on the centrifuge platform to capture the front view of the model ground movement.

\section{(1) The tunneling model}

Ground loss value is defined as the ratio of the volume of tunnel contraction $(\Delta V)$ divided by the volume of the tunnel per unit length $\left(V_{0}\right)$. To simulate the tunneling process in centrifuge models, various techniques have been applied. For example, in an oil volume control technique ${ }^{10}$ ), a syringe pump was fabricated to control the volume of silicone oil in the aluminum pipe which was covered by rubber bag.
Table 2 Properties of Toyoura sand.

\begin{tabular}{|c|c|c|c|c|c|}
\hline$G_{s}$ & $\begin{array}{c}D_{50} \\
(\mathrm{~mm})\end{array}$ & $U_{c}$ & $e_{\max }$ & $e_{\min }$ & $\emptyset^{\prime}$ \\
\hline 2.65 & 0.19 & 1.62 & 0.973 & 0.609 & $40^{\circ}$ \\
\hline
\end{tabular}

Similarly, air pressure method was also introduced with a reinforced rubber $\mathrm{bag}^{12)}$. Although the induced ground loss can be controlled by these methods, the boundary condition of tunnel perimeter could not be fully controlled or measured.

In this study, the mechanical tunnel machine ${ }^{13)}$, which can reduce the diameter size in co-axial direction was used as shown in Fig. 2. There are two layers of rubber membrane. The outer layer of rubber membrane is curled around the circular steel rings and these circular steel rings are attached at the holes front and back of the sand box as illustrated in Fig.2. Two open holes of sand box provide stoppers for the both steel rings, and the rings are tightened by screws. This outer layer is formed like a cylinder rubber tube to cover the tunnel machine. The tunnel machine covered with inner rubber membrane is inserted through this rubber tube and tightened with the screws.

This type of tunnel model can create a clear boundary condition from the start of contraction until the end of the process. The performance of tunnel machine is proved by comparing the distribution of normalized trough width and relative soil depth $(K)$ values along the depth with the result from Moh et al. $(1996)^{14)}$. They collected the results from construc- 
tion at Taipei Rapid Transit system (TRTS) in sandy ground. In this study, the distributions of $K$ values were analyzed by Particle Image Velocimetry (PIV) technique at the front screen and showed good agreement with Moh et al. (1996) ${ }^{14)}$.

This type of boundary condition could be relevant for the small ground loss, which is caused by the tail void of shield tunneling works in soft soils. It should be noted, however, that for the large ground loss condition, which corresponds to a critical condition, such as collapse of tunnel face or segment, relevant boundary conditions might be different from the one in this model.

\section{(2) The model piles}

Two piles with strain gauges and two uninstrumented piles were connected by stainless steel pile cap, which made $2 \times 2$ pile groups. To distinguish the pile behavior between front and rear pile, distance of 5 times pile diameter was selected to be utilized as the pile spacing. This spacing was wide enough to minimize the pile group effect. The pile models had two different embedment depths of $150 \mathrm{~mm}$ and 220 $\mathrm{mm}$ for the short and long piles, respectively. In the same model, the two pile groups were placed at the same horizontal distance between piles and tunnel center $\left(X_{p}\right)$, but at different relative depths $\left(Z_{p e}\right)$ from the tunnel center (Fig. 1). $X_{p}$ and $Z_{p e}$ were the parameters in the tests. Furthermore, on top of the pile caps, an acrylic or a stainless steel thick plate was placed to apply various vertical loads to the pile group as shown in Table 1.

The model piles were hollow acrylic tubes with thin brass caps to close the pile top and end. A total of 11 cases of tunneling test and 2 cases of pile-load test were conducted. The acrylic was quite flexible and had large yield strain. The tests were designed to make large ground loss ratio, which caused high strain in the pile model. The pile models certainly served as elastic materials in the tests and could be reused, which was the main reason for selecting the acrylic as pile model. In addition, after the tests, there was no dent or scratch left on the piles surface. Therefore, the multiple usage of acrylic piles did not interfere with the development of skin friction.

Strain gauges were placed inside the piles to measure the induced axial forces and bending moments during the reduction of the model tunnel diameter. The ultimate vertical load-bearing capacities, which were measured at $10 \%$ of the pile end settlement in vertical load tests, were $3600 \mathrm{kN}$ and 8000 $\mathrm{kN}$ in a prototype scale for the short and long piles, respectively. Pile models were designed to have a safety factor of 1.5 and 2.5 for heavy and light load cases, respectively. However, there were some limitations in the volume of weight block and relative density of weight block's material. The weight block sizes were the same for all test cases to control the initial conditions. Therefore, the safety factors were slightly different from the primary design. The flexural rigidity $(E I)$ and axial rigidity $(E A)$ were 0.093 $\mathrm{GNm}^{2}$ and $0.9 \mathrm{GN}$ in a prototype scale, respectively. The rigidities of model piles were slightly smaller than $1 \mathrm{~m}$ of concrete and steel pile.

\section{TEST PROCEDURE}

The sand used for the model ground was dry Toyoura sand. Properties of the sand are shown in Table 2. The pile groups were first suspended in the designed positions and then dry Toyoura sand was pluviated by a sand hopper with long tube to make a target relative density of $80 \%$.

At centrifugal acceleration of $100 \mathrm{~g}$, the diameter of the model tunnel was reduced continuously to make ground loss ratio $\left(\Delta V / V_{0}\right)$ from $0 \%$ to $15 \%$. In model scale, radius of tunnel reduction $(\Delta R)$ was equal to $0.35 \mathrm{~mm}$ and $2.73 \mathrm{~mm}$ at $2 \%$ and $15 \%$ of ground loss, respectively. The mean grain diameter $\left(D_{50}\right)$ of dry Toyoura sand was equal to $0.19 \mathrm{~mm}$.

During the tunneling, images of the front view of the model ground were captured by a digital camera (Canon Power shot G7) to measure the subsoil displacement by PIV technique ${ }^{15}$. The pile group displacements were measured with sets of laser displacement transducers (LVDTs) and potentiometers (PTMs), along with soil surface movements by PTMs. Induced axial force and bending moment of piles during the test were also monitored ${ }^{16)}$. The behaviors of piles were discussed according to the zones of influence ${ }^{17)}$ defined from the tunnel to the soil surface.

The relative size of the pile diameter $(10 \mathrm{~mm})$ to the median soil grain size $\left(D_{50}\right)$ was 50 , which is above the suggested value $20 \sim 30$ to avoid the grain size effects on pile capacity ${ }^{18), 19 \text { ). }}$

\section{TEST RESULTS}

\section{(1) Ground movement and zone of influence}

The settlement profiles induced by a tunnel can be approximated as a normal probability (Gaussian) curve $^{12)}($ Fig.3). Fig.4 and Fig.5 show the displacement vectors and subsurface vertical displacement $\left(v_{z}\right)$ profiles obtained by the PIV analysis for Case $0-\mathrm{D}$, respectively. The horizontal distance from the tunnel axis $(x)$ and the vertical displacement are normalized by the initial tunnel radius $(R)$ and the decrement of the radius $(\Delta R)$ in Fig.5. 


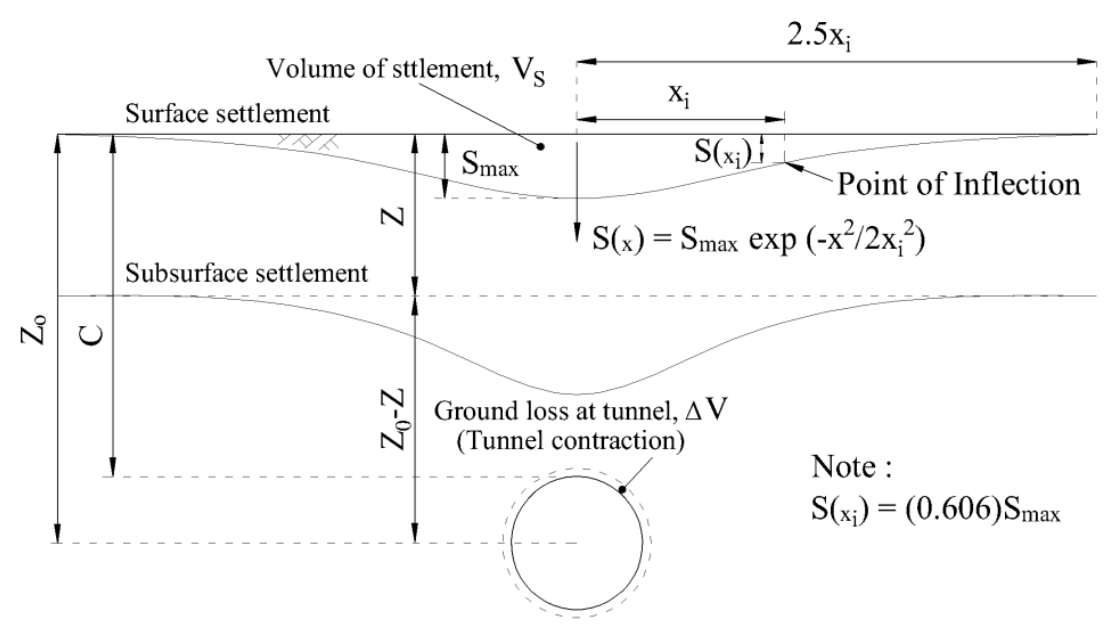

Fig.3 Parameters and settlement profile described by normal distribution curve.

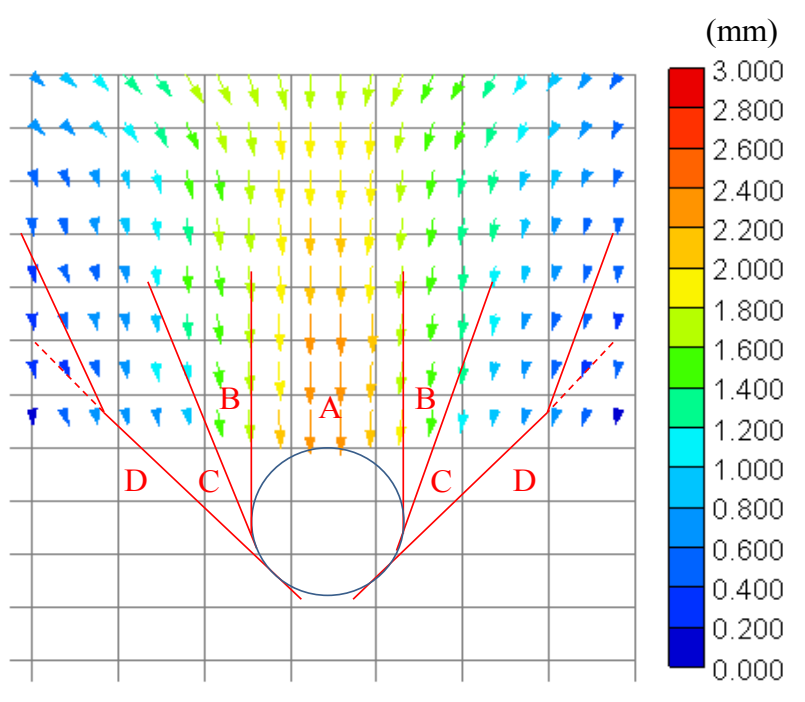

Fig.4 Displacement vectors from PIV: Case $0-\mathrm{D}, \Delta V / V_{0}=15 \%$.

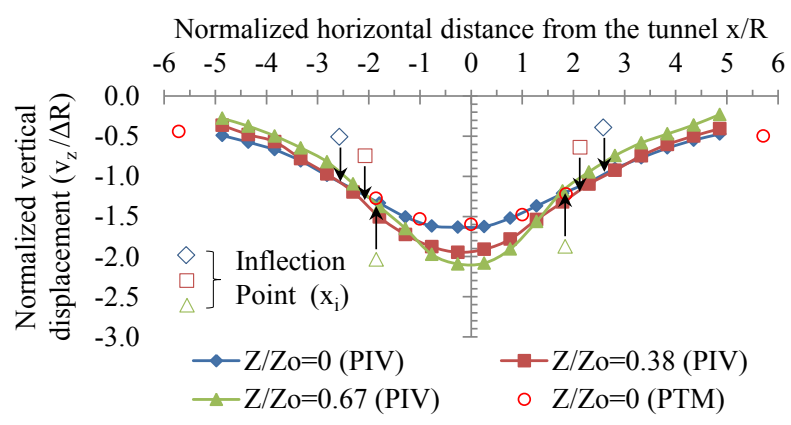

Fig.5 Subsurface soil settlement profiles: Case $0-\mathrm{D}, \Delta V / V_{0}=2.0 \%$.

In the figure, the surface settlements measured by PTMs are also plotted and the positions of infection point $\left(x_{i}\right)$ are shown by arrows. The inflection point is defined at 0.606 times of maximum surface settle- ment at the center line of tunnel $\left(S_{\max }\right) .{ }^{14), 20)}$

The surface settlements measured by the PIV and PTMs are almost identical, showing the accuracy of PIV measurement. Overall ground displacements are directed toward the tunnel axis. The width of settlement trough in terms of $x_{i}$ decreases with depth.

Based on the settlement behavior of single pile in a dense dry sand observed from centrifuge tunneling tests, Jacobsz et al. ${ }^{17)}$ introduced the zone of influence near the tunnel as shown in Fig.6. For the zoning, four lines are introduced: lines $a$ and $b$ from the spring line with horizontal angles of 90 degrees and $45+\varphi^{\prime} / 2$ degrees, respectively: line $d$ tangent to the tunnel toe at 45 degree: and line $c$, which was drawn from the point of $2 x_{i}$ at the ground surface to bound the pile tip location for the large settlement and small settlement of the piles induced by tunneling as shown in Fig.6. The large settlement was defined as larger than 0.022 times pile diameters at a ground loss ratio of $1.5 \%$. From the test results, it was concluded that the behavior of piles settlement depended on their pile end positions. In Zones A and $\mathrm{B}$, the piles settled rapidly from the beginning of tunneling and underwent very large magnitude of settlement. While in Zone $\mathrm{C}$, the settlement rate gradually increased, finally giving relatively large magnitude of settlement. However, in Zone D the effect of tunneling was limited, causing a small pile settlement ${ }^{17)}$.

In this study, a similar zone of influence was adopted for the model of $C / D=2.5$ and 1.5 as shown in Fig.7. For the zoning, lines $a, b$, and $d$ are drawn in the same manner as those by Jacobsz et al. ${ }^{17)}$, but line $c$ was made by connecting the coordinates of two times of inflection point $\left(2 x_{i}(z), z\right)$ from the soil surface to the intersect point on line $d$, where $x_{i}(z)$ is- 


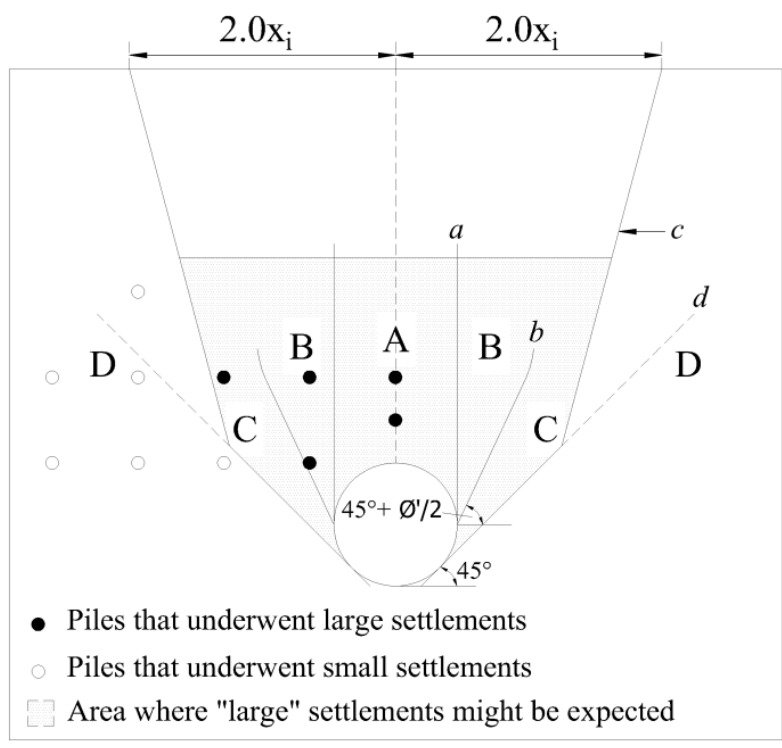

Fig.6 Zone of influence by Jacobz et al. ${ }^{17)}$.

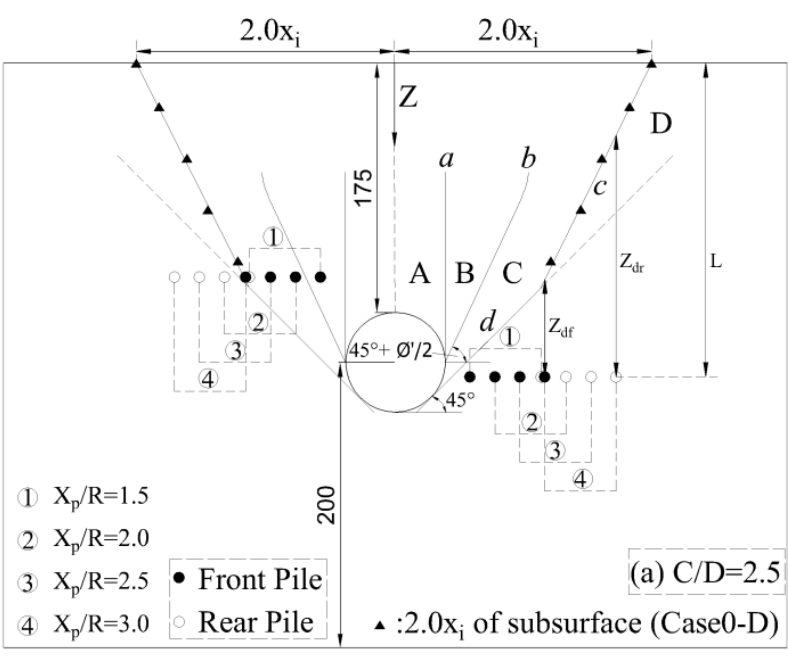

(a) Case $0-\mathrm{D}$

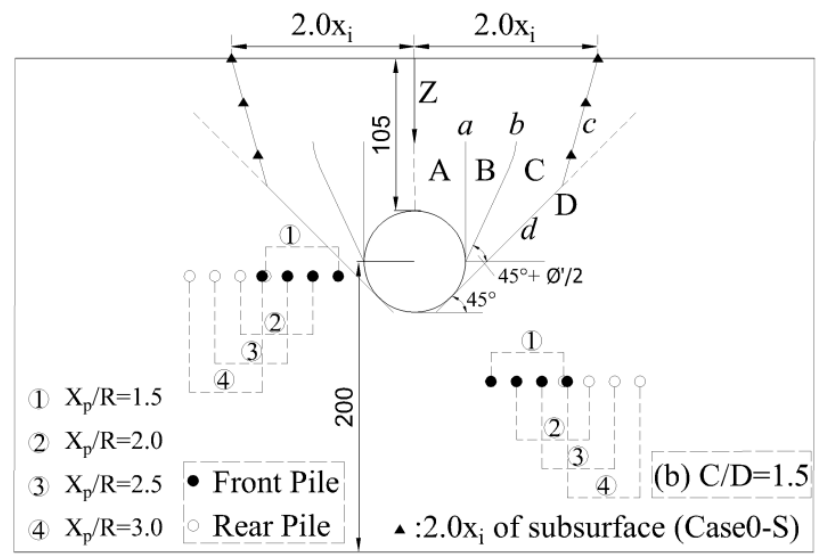

(b) Case $0-\mathrm{S}$

Fig. 7 Zones of influence defined in this study and the pile base positions for the short and long piles with different horizontal distance from tunnel center $\left(X_{p}\right)$ and cover and depth ratio $(C / D)$ within zone of influence.

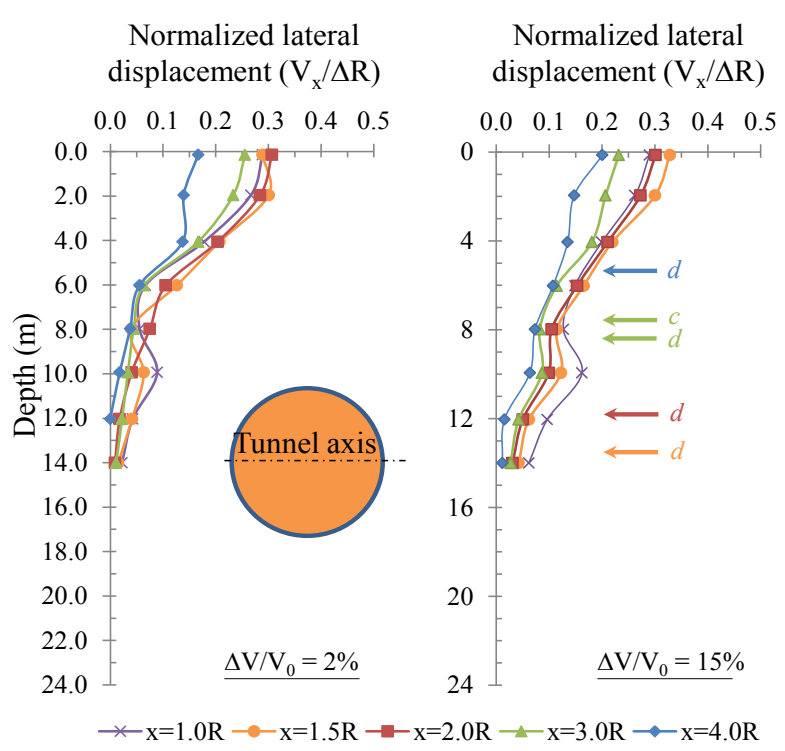

(a) Case $0-\mathrm{S}, \mathrm{C} / \mathrm{D}=1.5$

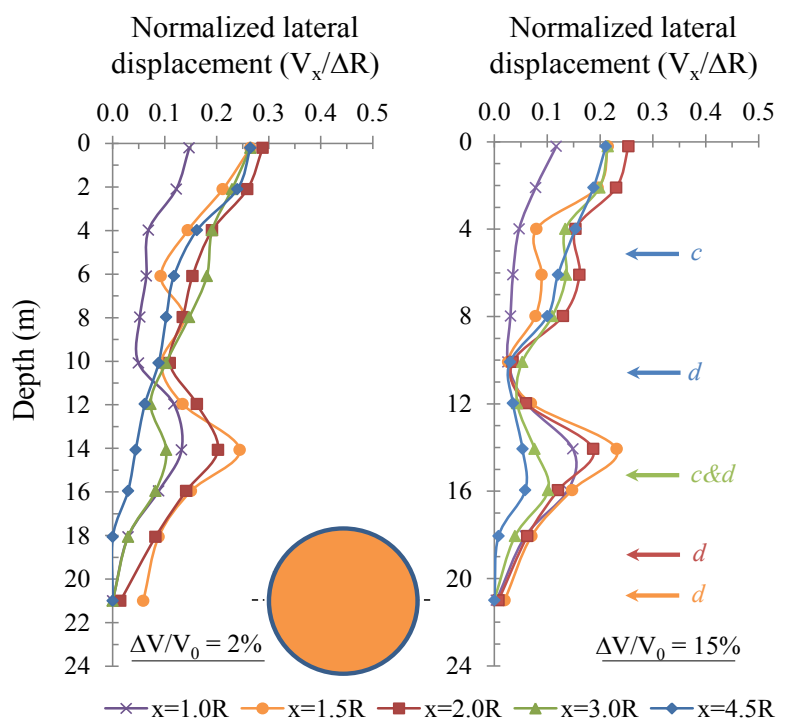

(b) Case $0-\mathrm{D}, \mathrm{C} / \mathrm{D}=2.5$

Fig. 8 Normalized lateral soil movements along the depth with various relative horizontal distance $\left(X_{p} / R\right)$ at the ground loss of about $2 \%$ and $15 \%$, with the depth of the boundary between Zone $\mathrm{C}$ and $\mathrm{D}$.

the horizontal location of the inflection point of the subsurface settlement profile at depth $z$. In Case0-D, $z$ values are equal to $0 \mathrm{~mm}, 30 \mathrm{~mm}, 66 \mathrm{~mm}, 102 \mathrm{~mm}$, and $138 \mathrm{~mm}$. In Case $0-\mathrm{S}, z$ values are equal to $0 \mathrm{~mm}$, $30 \mathrm{~mm}$, and $66 \mathrm{~mm}$.

Because the width of the inflection points showed linear reduction along the soil depth, line $c$ could be drawn by connecting those inflection points until it is intersected on line $d$. In the figures, the locations of front and rear pile tips are indicated for short and long piles in the cases with different $X_{p}$. 


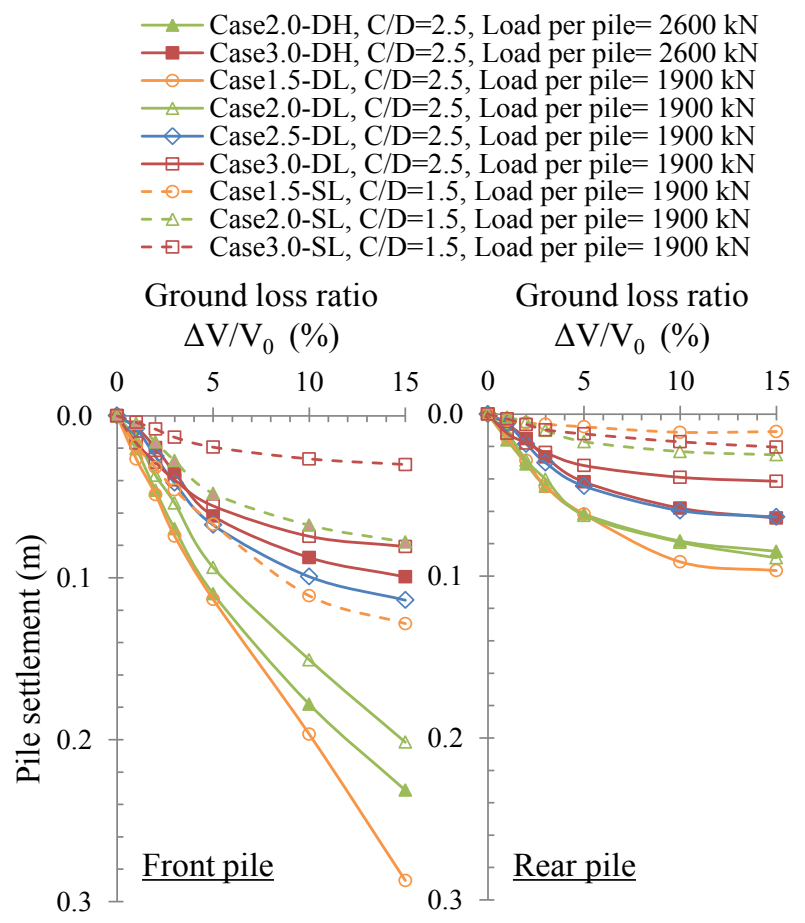

(a) Short piles

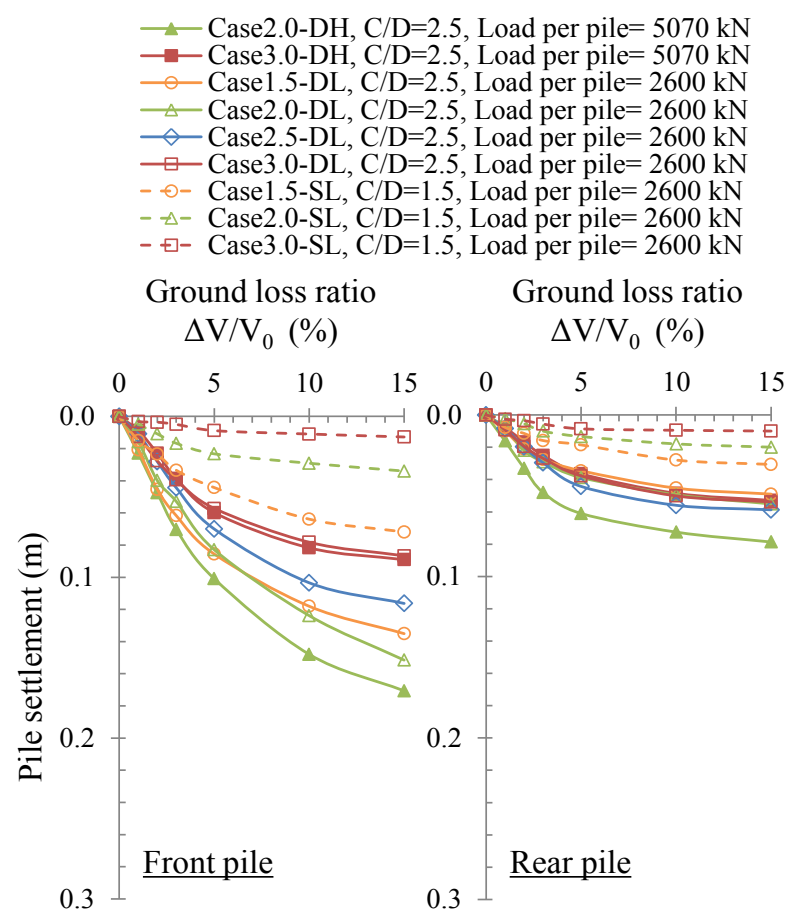

(b) Long piles

Fig. 9 Settlement of the front and rear piles during tunneling.

Fig.8 shows the lateral soil displacement $\left(v_{x}\right)$ profile with depth at the horizontal locations $(x)$ from $1.0 R$ to $4.5 R$. The lateral displacement toward the tunnel direction is taken as a positive and it is normalized by the decrement of tunnel radius $(\Delta R)$ in the figure. The depths of lines $c$ and $d$ at each location are also shown in the figure.
Both in the cases with $C / D=2.5$ and 1.5 at the small and large ground loss ratio $\left(\Delta V / V_{0}\right)$, large lateral displacement took place near the soil surface and it decreased with depth. However, the large lateral movements also occurred slightly above the tunnel, which was more distinct at the large ground loss ratio, especially for the case with larger $C / D$ at $X_{p}$ less than 2.0R. It should be noted that the lateral displacements at the depth of line $d$ were similar for the different lateral locations and they sustained small values as compared to the depth above line $d$.

\section{(2) Pile settlement}

In Fig. 9, the settlements of front and rear piles are plotted against ground loss ratio. In the tests with large tunnel cover depth ratio $(C / D)$, the settlements increased with increase in the ground loss ratio and the front piles settled larger than the rear piles for all the cases. The cases with heavy working loads (Case2.0-DH, Case3.0-DH) showed more settlement than the cases with light working loads (Case2.0-DL, Case3.0-DL), but the trends of settlement were similar. For the small ground loss ratio $\left(\Delta V / V_{0}\right.$ less $\left.3 \%\right)$, the settlements increased linearly with $\Delta V / V_{0}$. While for $\Delta V / V_{0}$ over $3 \%$, the settlement rates gradually decreased and became very small at the end of the tests $\left(\Delta V / V_{0}=15 \%\right)$, except for the short front piles in Case1.5-DL, Case2.0-DL and Case2.0-DH. These piles showed large settlements, which were almost proportional to the ground loss ratio even for $\Delta V / V_{0}$ over 5\%. As indicated in Fig.7, the ends of the short front piles in Case1.5-DL located in Zone B and those in Case2.0-DL and Case2.0-DH were close to Zone B in Zone C. The ends of all other piles, including the short front pile with $X_{p} / R>2$, all short rear piles and all long front and rear long piles rested on Zone D or boundary between Zones C and D.

The closer the pile to the tunnel, the larger the settlement took place, except for the long front piles of Case1.5-DL and Case2.0-DL, which had large cover depth ratio $(C / D=2.5)$, and the pile end depth close to the tunnel axis $\left(Z_{p e} / R=0.28\right)$. For $\Delta V / V_{0}$ over $5 \%$, the settlement for the former with $X_{p} / R=1.5$ became slightly smaller than the latter with $X_{p} / R=2.0$. For the short front piles of Case1.5-SL and Case2.0-SL with small cover depth ratio $(C / D=1.5)$ and the same $Z_{p e} / R(=0.28)$, the settlement for the former was larger than that for the latter.

\section{(3) Pile cap movements}

For safety assessment of superstructures, it is important to predict not only the movement of the structure and the vertical settlement $(\delta z)$, but also the lateral movement $(\delta x)$ and inclination $(\theta)$. 


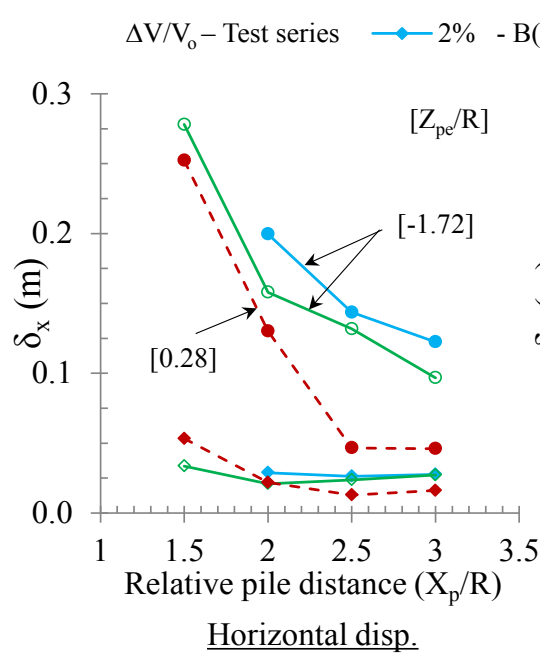

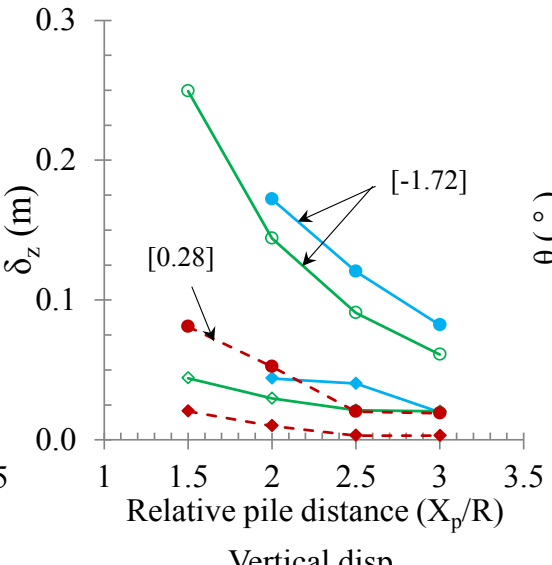

Vertical disp.

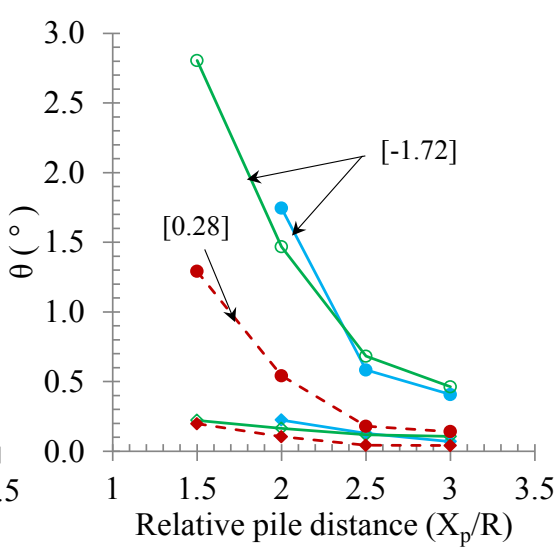

$\underline{\text { Inclination }}$

(a) Short pile groups

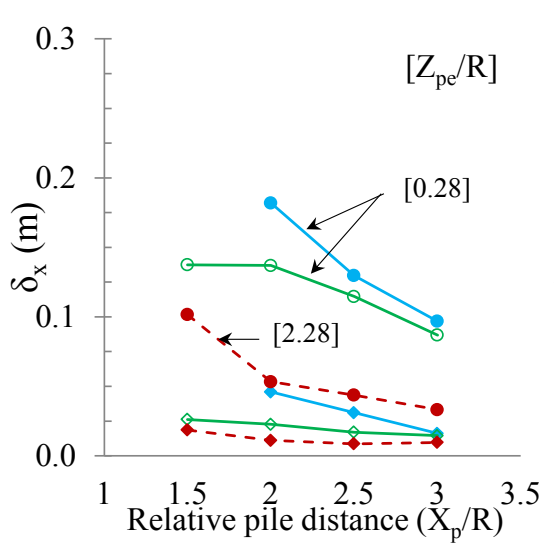

Horizontal disp.

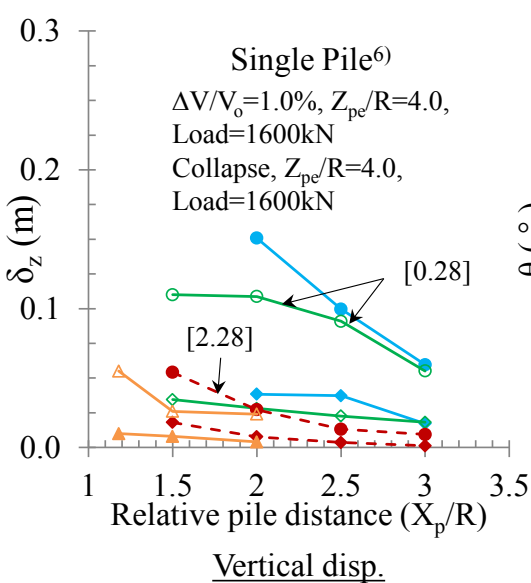

Vertical disp.

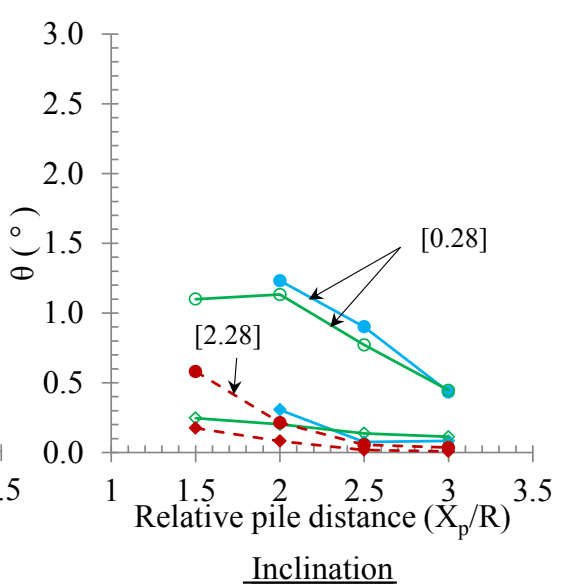

Inclination

(b) Long pile groups

Fig. 10 Comparison of horizontal and vertical displacements, and inclination of the pile cap at the ground loss ratio of $2 \%$ and $15 \%$ with relative distance $\left(X_{p} / R\right)$.

In Fig.10, the three components of pile cap movements are plotted against relative horizontal distance $\left(X_{p} / R\right)$ at ground loss ratios $\left(\Delta V / V_{0}\right)$ of $2 \%$ and $15 \%$. These relatively small and large ratios are considered as possible normal working conditions and a critical condition close to a failure of tunnel.

The effects of applied vertical load to the foundation were investigated by comparing case series $\mathrm{B}(1)$ and $\mathrm{B}(2)$. The effects of cover and depth ratio $(C / D)$ were also illustrated by case series $\mathrm{B}(2)$ and $\mathrm{C}$. The results of vertical settlement of single pile ${ }^{9)}$ with various $X_{p} / R$ were also shown in the long pile group curves.

The horizontal and vertical displacements of the pile groups $\left(\delta_{x}, \delta_{z}\right)$ with large vertical load were larger than those with smaller load. However, the effect of the vertical load on the inclination was less, compared to those on $\delta_{x}$ and $\delta_{z}$. In the figure, relative pile depths to the tunnel axis value $\left(Z_{p e} / R\right)$ of each case- series are indicated in square brackets. The pile group with smaller $Z_{p e} / R$ showed larger pile cap movements than those with larger $Z_{p e} / R$ for both short and long pile groups. However, for the short pile groups with the light vertical loads, the horizontal displacements of the cases with $Z_{p e} / R=0.28$ showed large increase from $X_{p} / R=2.5$ and had almost similar magnitudes to those of the cases with $Z_{p e} / R=-1.72$ for $X_{p} / R$ less than 2.0.

As the pile group was close to the tunnel and the pile length increased, the more pile portions rested in Zones $\mathrm{B}$ and $\mathrm{C}$. The short pile groups with the front pile ends resting in Zones $\mathrm{B}$ and $\mathrm{C}\left(Z_{p e} / R=-1.72\right)$ showed larger pile cap movements in all the components than those resting in Zone $\mathrm{D}\left(Z_{p e} / R=0.28\right)$. For the short pile groups with $Z_{p e} / R=0.28$, there were no difference in the movements for $X_{p} / R$ over 2.5, but the distinct increase of the movements were measured for $X_{p} / R$ less than 2.5 . 


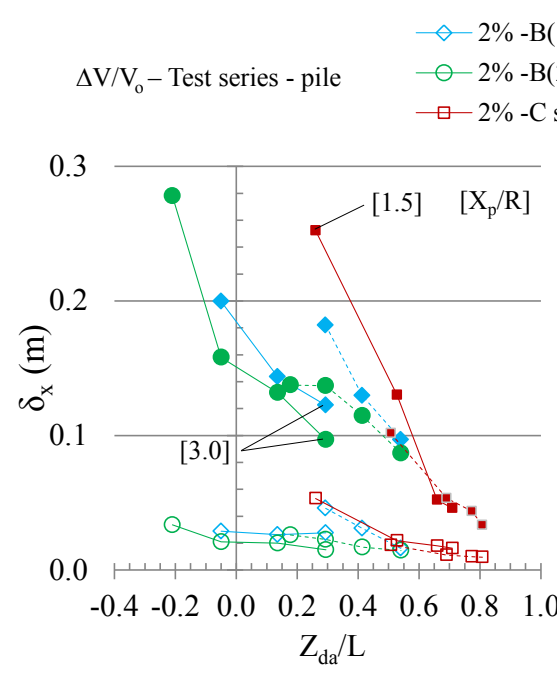

Horizontal disp.

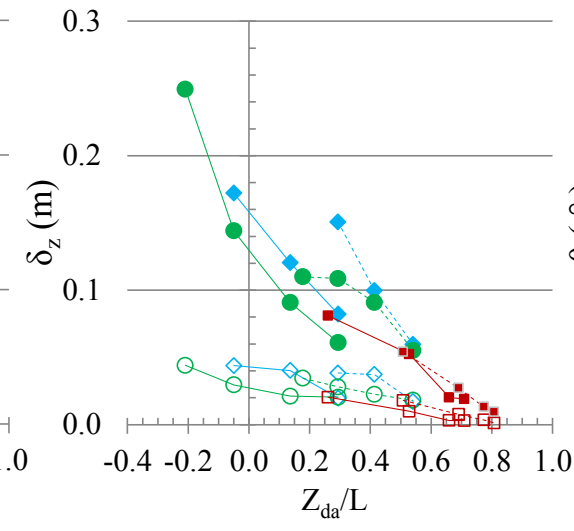

Vertical disp.
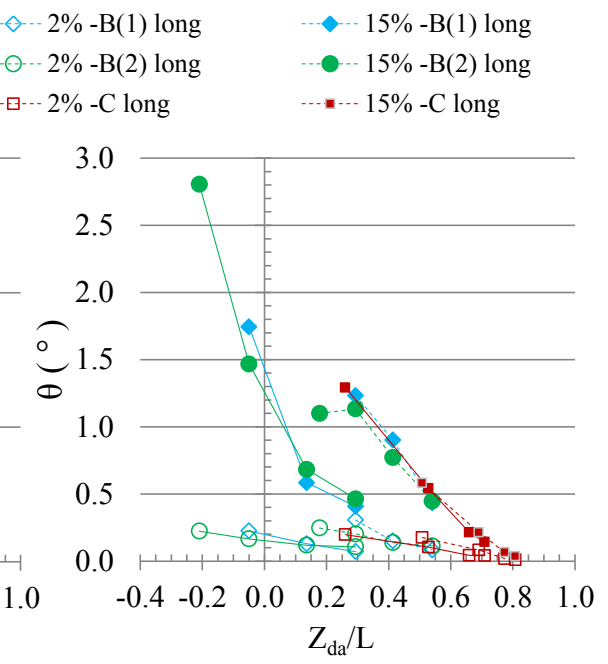

Inclination

(a) Normal scale

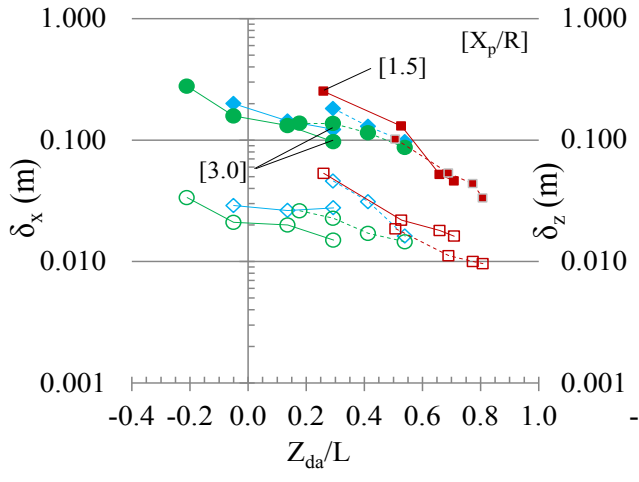

$\underline{\text { Horizontal disp. }}$

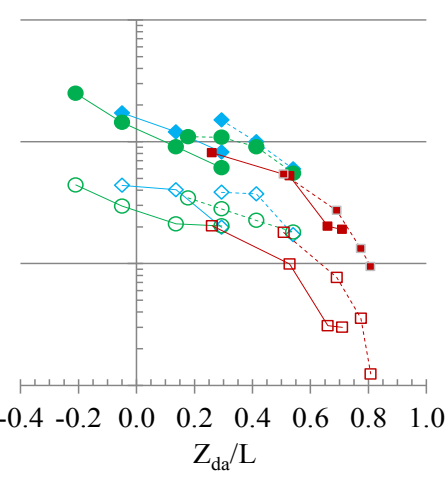

Vertical disp.

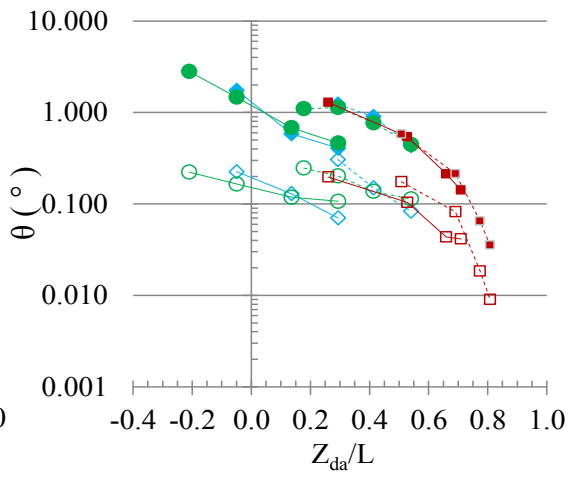

Inclination

(b) logarithmic scale

Fig. 11 Relationships between the pile cap movements at the ground loss ratio of $2 \%$ and $15 \%$ and average relative depth from the boundary of Zone C and D.

The long pile groups with large embedment depth $\left(Z_{p e} / R=2.28, C / D=1.5\right)$ developed large pile cap movements when the relative pile distance was less than 2.0. In the figure on vertical displacement of long pile (Fig. 10(b)), the results obtained in similar tests on a single pile with $Z_{p e} / R=4.0^{9)}$ are compared. The single pile also shows a large increase as the pile is close to the tunnel. But the threshold value on $X_{p}$ (less than 1.5) is smaller than that obtained in this study ( $X_{p}$ less than 2.0) for the piles with $Z_{p e} / R=2.28$.

For the long pile groups with $Z_{p e} / R=0.28$, the movements increased as the pile became close to the tunnel for $X_{p} / R$ from 3.0 to 2.0. But for $X_{p} / R$ less than 2.0, no significant increase in the movements was observed for the long pile with $Z_{p e} / R=0.28$ as compared to those of the short pile group with the same $Z_{p e} / R$. Although no apparent reason could be derived, it could be caused by the relatively small settlement of the long front pile with $X_{p} / R=1.5$ than that with
$X_{p} / R=2.0$ as shown in Fig.9 (b).

As shown in Fig.10, the displacements of pile cap are significantly influenced by $X_{p} / R$ and $\mathrm{Z}_{\mathrm{pe}} / R$. In this study, the pile end depth from the boundary of Zones $\mathrm{C}$ and $\mathrm{D}, Z_{d}$, was considered as a parameter that reflected the effects of $X_{p}$ and $Z_{p e}$ (Fig.7). In Figs.11(a) and 11(b), three displacement components are plotted against $Z_{d a} / L$ (eq.(1)) at $\Delta V / V_{0}=2 \%$ and $15 \%$.

$$
\frac{Z_{d a}}{L}=\left(\frac{Z_{d f}+Z_{d r}}{2}\right)\left(\frac{1}{L}\right)
$$

where $Z_{d a}$ is average $Z_{d}$ of the front pile $\left(Z_{d f}\right)$ and rear pile $\left(Z_{d r}\right)$, and $L$ is the pile embedment length. $Z_{d f}$ and $Z_{d r}$ are the pile portions that rest in the less displacement zone (Zone D) of front and rear pile, respectively. Because the pile cap movements are in- 
fluenced by both front and rear piles, the average values of $Z_{d}$ from front and rear pile are utilized.

The pile cap movements caused by tunneling should be reduced as the increment of values of $Z_{d a} / L$ (see also Fig.11), meaning that more pile portions rest in stable soil region. If the pile horizontal distance $\left(X_{p}\right)$ is farther than two times of the horizontal inflection point $\left(x_{i}\right)$ measured at soil surface, the normalized values of $Z_{d f} / L$ and $Z_{d r} / L$ will be equal to 1.0. Therefore, the value of $Z_{d a} / L$ will be limited at 1.0. In addition, this proposed equation (1) should be utilized when one of the pile ends is not shallower and deeper than $2.5 \mathrm{D}$ from the tunnel center because the effect of tunneling is insignificant if the pile end rests outside those ranges ${ }^{10), 17), 21 \text { ). }}$

The displacements are shown in normal scale and logarithmic scales in Figs.11(a) and 11(b) to discuss the behavior for both small and large ground loss ratios. Negative value or small value of $Z_{d a} / L$ means the front pile of the pile group rests in Zone B or close to the boundary between Zones B and C. From Fig.11(a), it can be confirmed that the condition of the front and rear piles resting in the large soil movement zone and less-movement zone (Zone D), respectively, caused large uneven settlement of the pile group, resulting in large lateral movement and inclination at the pile cap. This large differential settlement in the large soil movement region (front pile) and small soil movements region (rear pile) is also observed. ${ }^{7)}$

There is a unique relation between the inclination and $Z_{d a} / L$ for the cases with the pile end depth deeper than the tunnel axis, regardless of pile length and tunnel cover and depth ratio, which is quite different from the relation in the case where the pile end depth is shallower than the tunnel crown. The horizontal and vertical displacements also show some correlations with $Z_{d a} / L$, but not so obvious as compared to that for the inclination. A large difference in the horizontal displacement for the long and short pile can be seen at $Z_{d d} / L$ from 0.5 to 0.3 . The difference could be attributed to the difference in lateral soil displacement profile between the cases of $C / D=1.5$ and 2.5. The horizontal displacements near the ground surface (Fig.8) were not so different from $x=1.5 R$ to $4.5 R$ for the large $C / D$. For the small $C / D$, however, it showed the larger value at $x=1.5 R$ to $2.0 R$ and significantly reduced as $x$ increased.

The effect of $X_{p}$ became small when the piles end rested deeper than lines $c$ and $d$ of the zone boundary $\left(Z_{d a} / L>0.5\right)$, which can be confirmed for all three components of pile cap movement of the long pile groups in the case $\mathrm{C}$ series. As the zoning was made based on the vertical soil displacement, there was a limitation in the applicability of $Z_{d a} / L$ as a parameter, which includes the effects of both $X_{p} / R$ and $Z_{p e} / R$.
The zone of influence could be related to the arching zone ${ }^{22)}$. Lee et al., $2006^{23)}$ studied the arching effect of tunneling in sandy soil caused by tunneling. An arching ratio was defined by the changing of normalized effective vertical stress during the increment of ground loss ratio. The areas near the tunnel within the zone of large soil movement would experience the negative arching ratio, and positive arching ratio could be observed in the less movement of soil. Variations in cover depth $(C)$ also affect the shape of influence zoned ${ }^{24), 25)}$, and hence affect the area of arching ratio. The zone of influence would be narrowed and showed majority of soil movement in the region directly above the tunnel (chimney-like displacement mechanism) for small cover and depth ratio $(C / D)$. On the contrary, the zone of influence would be widened and showed ambiguous shape of chimney-like displacement mechanism for large cover and depth ratio $(C / D)^{24)}$.

\section{(4) Behavior of pile response}

\section{a) End bearing load of the pile groups}

Fig.12 shows the variations in pile end bearing loads with the ground loss ratio ranging from $0 \%, 1 \%$, $2 \%, 3 \%, 5 \%, 10 \%$, and $15 \%$. The loads shown in the figure are absolute values and the end bearing load at the beginning $\left(\Delta V / V_{0}=0 \%\right)$ is the load prior to starting the tunnel diameter contraction.

The variations in the pile end bearing were larger for the front pile than for the rear pile. The short front piles in Case1.5-DL, Case2.0-DH, and Case2.0-DL, which showed large settlement (Fig.9(a)), underwent reductions in the end bearing load during the ground loss, especially for that in Case1.5-DL, resting in Zone B. In contrast, the measured axial force increased with increase in the ground loss ratio for cases with pile resting in Zone D both for the front and rear piles. The results are similar to previous studies ${ }^{7}$. Therefore, to clearly show the influence of relative position between the zone of influence and pile ends, the settlement of the short front pile positions (Fig. 9(a)) were plotted against the end bearing load (Fig. 12) as illustrated in Fig. 13. The cases with the decrement of the end bearing load showed large pile settlement, especially for Case1.5-DL with $X_{p} / R=1.5$ (resting in Zone B). In contrast, pile groups with the pile tip resting in Zone D (Case3.0-DH, Case3.0-DL, and Case 1.5-SL) endured small pile settlement and were capable of conveying more axial force.

\section{b) Axial forces along the piles}

Fig. 14 shows the profiles of pile axial force for various parameters, such as the horizontal distances from tunnel $\left(X_{p}\right)$, the cover and depth ratios $(C / D)$ and the working loads. 


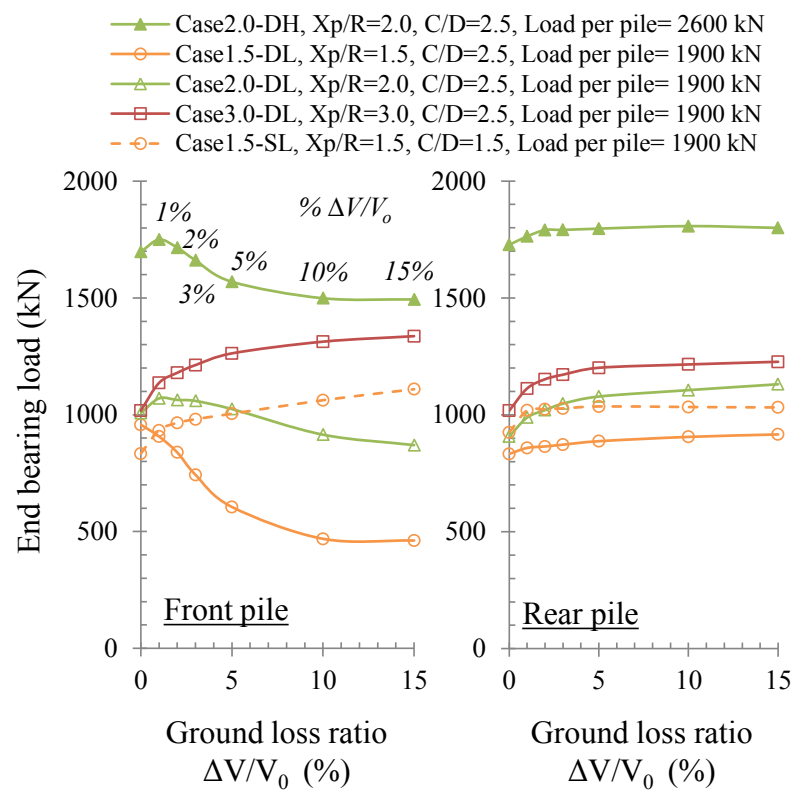

(a) Short piles group

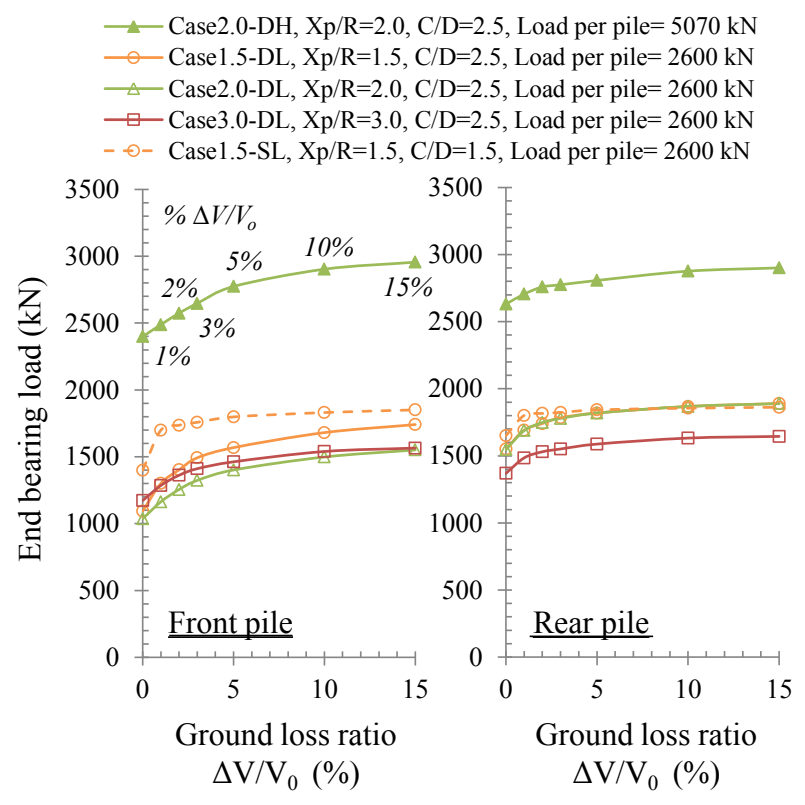

(b) Long piles group

Fig. 12 Variation of pile end bearing load with ground loss ratio.

The profiles at two different ground loss ratios $\left(\Delta V / V_{0}=2 \%\right.$ and $15 \%$ ) show the comparison between normal working load and failure load conditions. The reductions of the end bearing were observed in the short front piles of Case2.0-DH and Case2.0-DL, where the piles rested in Zone $\mathrm{B}$ and close to the boundary between Zone B and C, respectively. Some piles showed the reduction of axial force at the pile head, which corresponded to the previous study ${ }^{26}$. The performance of axial strain gauges showed good accuracy because the measured pile head load and load per pile in test conditions (Table 1) were almost identical.

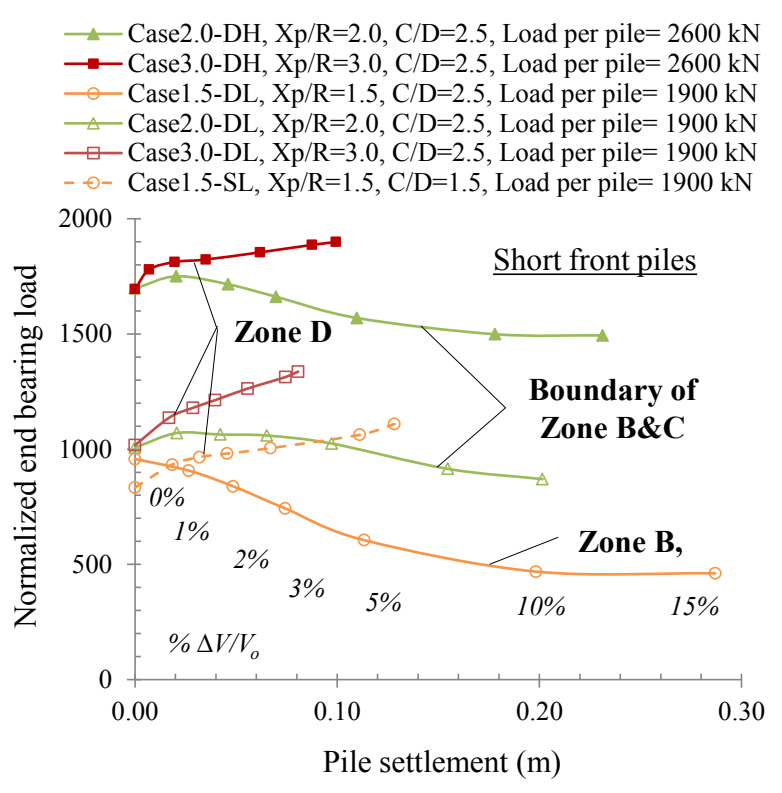

Fig. 13 Variation of pile end bearing load with pile settlement, short front piles.

Pile groups with different loads on the pile cap (case $\mathrm{B}(1)$ and case $\mathrm{B}(2)$ series) developed similar shapes of induced axial forces. However, there were differences in the shape and magnitude of the axial force profiles of the piles with different horizontal distance of piles and tunnel $\left(X_{p}\right)$, and cover and depth ratio $(C / D)$. The outcomes may correspond to the relative position between the piles and the zone of influence.

\section{c) Development of skin friction}

Pile bearing capacity $\left(Q_{u}\right)$ is carried by point end bearing $\left(Q_{p}\right)$ and skin friction $\left(Q_{s}\right)$.

$$
Q_{u}=Q_{p}+Q_{s}
$$

where $Q_{p}$ is the load carried at the pile base, and $Q_{s}$ is the load carried by the skin friction of the pile shaft.

In the study, the average unit skin friction $f(z)$ was calculated by the following equation:

$$
f(z)=\frac{\Delta Q_{z}}{s(\Delta z)}
$$

where $\Delta Q_{z}$ is the difference of measured axial force between two points along the pile model, $s$ is the perimeter of pile cross-section, and $\Delta z$ is the distance between the two points of axial force measurement.

Fig. 15 depicts the mobilization of the average unit skin friction along the piles, which was obtained from the measured axial forces (Fig. 14). The skin friction is mobilized by the relative displacement between model pile and surrounding soil. It becomes 
positive (upward) when the vertical pile displacement is larger than that of the surrounding soil, and negative (downward) when the pile displacement is less than the surrounding soil. In general, the front and rear piles showed similar shapes of average unit skin friction, but the rear piles developed less magnitude than the front piles.

In the figure, the depths of lines $d$ and $c$ at the location of piles are indicated by arrows. Inside Zones $\mathrm{B}$ and $\mathrm{C}$ (above lines $d$ or $c$ ), negative skin friction was developed due to large soil movements as shown in the short and long front piles of all the cases. However, some portions of the short front piles showed positive skin friction due to a large pile settlement. At the lower portion of the pile, the cases with small $X_{p} / R$ (the short front pile of Case2.0-DH and Case2.0-DL) developed a large negative skin friction even for the large magnitude of pile settlement (Fig. 9). However, they developed positive skin friction at the upper portion of the pile. These results could have come from the large soil movements near the depth of pile ends. But as the movements were reduced near the soil surface, the skin friction became positive due to the relatively large pile settlement.

In case $\mathrm{B}(1)$ and $\mathrm{B}(2)$ series (Figs. 15 (a) and (b)), most of the long piles developed negative skin friction along the length except the near pile end for the cases with $X_{p} / R \geq 3$ (Case3.0-DH and Case3.0-DL). In these piles, the positive skin frictions were generated at the lower portion due to small magnitude of soil movement in Zone $\mathrm{D}$ (below lines $d$ and $c$ ).

In cover and depth ratio equal to 1.5 (Fig. 15 (c)), the trends of mobilized skin frictions of the short and long piles were similar, which depended on the pile positions in the zones of influence. At the lower portion of the piles, positive skin frictions were generated for the long front pile with $X_{p} / R \leq 2.0$ because of relatively large pile settlement and small magnitude of soil movement in the deep zone.

While at the mid-depth near the tunnel axis, the long front pile with $X_{p} / R \leq 2.0$ (Case2.0-SL) developed large negative skin friction. This reduction of skin friction could have come from the loss of lateral earth pressure around the tunnel combined with large downward movements of the surrounding soil.

\section{d) Bending moments along the pile groups}

In Fig. 16, measured pile bending moment increments are shown for various horizontal distances from the tunnel $\left(X_{p}\right)$, cover and depth ratios $(C / D)$ and working loads. The depths of lines $d$ and $c$ at the location of each pile are also shown in the figure. The positive and negative signs of the bending moment mean that the pile bends away and toward the tunnel, respectively.

From Figs. 16 (a) and (b) on series $\mathrm{B}(1)$ and $\mathrm{B}(2)$, it can be seen that the working load on the pile groups has slightly influenced the shape of the bending moment profiles, but the lateral position of the pile $\left(X_{p} / R\right)$ has distinct influence on the shape of the bending moment profiles. Furthermore, the effect of cover and depth ratio $(C / D)$ were also significant. The effects of the parameters on the bending moment are similar to the previous study ${ }^{9), 10)}$.

The trends of bending moments were similar between front and rear piles at shallow depth. The bending moment near the pile top could be controlled by the displacements and rotation for a rigid fixity of the pile to the cap. For example, the short pile group with the front pile rested in Zone B or close to Zone B in Zone $\mathrm{C}$ (Case2.0-DH, Case1.5-DL and Case2.0-DL) in the condition of $Z_{p e} / R=-1.72$, large maximum negative bending moments were developed at the pile top. The larger the horizontal displacement was, the larger the moment. However, due to less confinement at the pile end, the lower portion of those piles showed small induced bending moment.

For the pile with relatively deep embedment depth to the tunnel and resting in Zone D, the bending moment profiles were different from those with the front pile resting in or close to Zone B. There were several peaks in the profile, and the location and magnitudes of the peak value depended on $X_{p} / R$ and $Z_{p e} / R$. The long front piles with $Z_{p e} / R=0.28$ had a peak moment at the depth slightly above the tunnel crown, but positive peak values for $X_{p} / R$ less than 2.0 and negative for $X_{p} / R=3.0$. The difference in the confinement at the pile end could be a reason for the difference in the sign of the peak moment. It should be noted that very similar moment profiles were observed in the long pile group, both in the front and rear piles between Case 1.5DL and Case2.0DL, implying similar horizontal forces loaded for the two pile groups. This could be one of possible reasons for the similar pile cap displacements of the two cases (Fig.10(b)).

For the cases with the small cover and depth ratio $(C / D=1.5$ in the case $\mathrm{C}$ series), a peak negative bending moment was generated in the long front piles near the tunnel, due to the large horizontal soil movement at the depth above the tunnel crown and small movement in Zone D below line $d$ (Fig.8). This peak moment became significant for the location of $X_{p} / R$ less than 2.0.

The moment of the pile was mainly caused by the ground movement at the deeper depth, but at the shallow depth or the top it was mostly determined by the pile cap displacements with the rigid fixity of the pile head. 


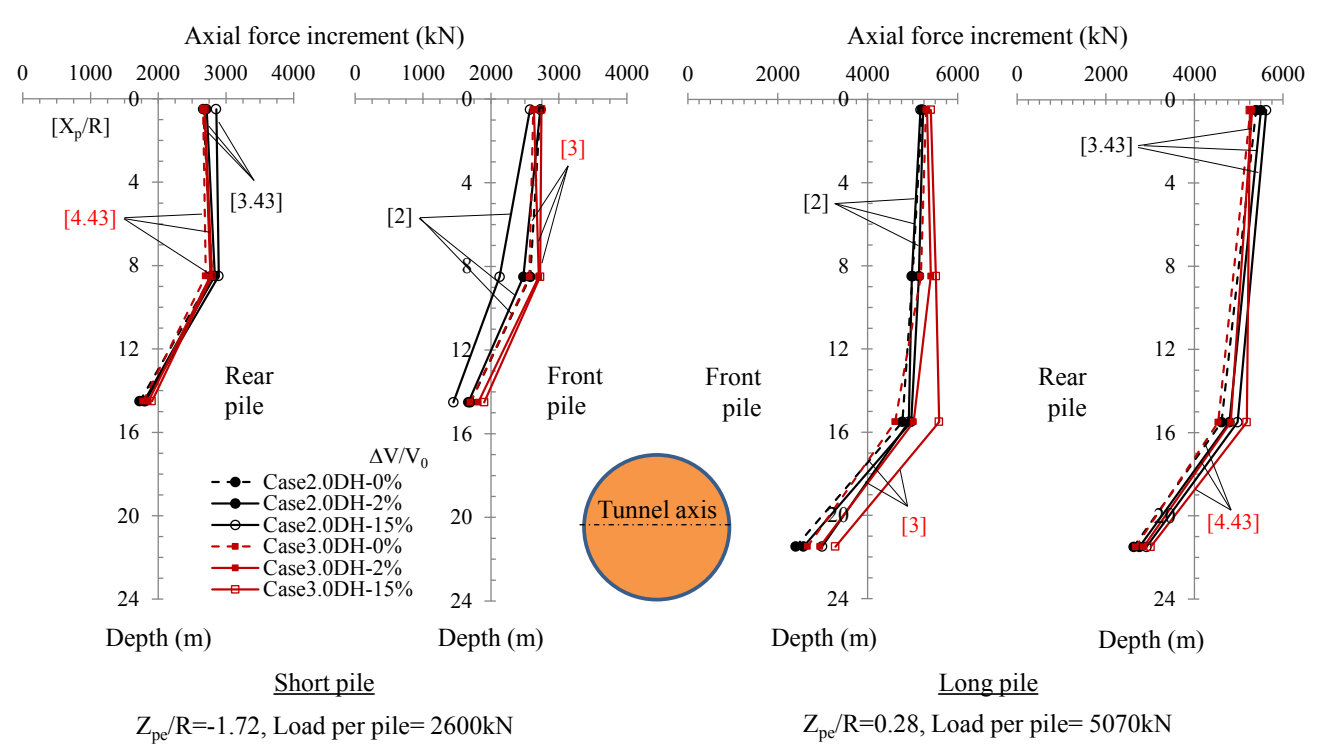

(a) $\mathrm{B}(1)$ series $(C / D=2.5)$

Axial force increment $(\mathrm{kN})$

Axial force increment $(\mathrm{kN})$

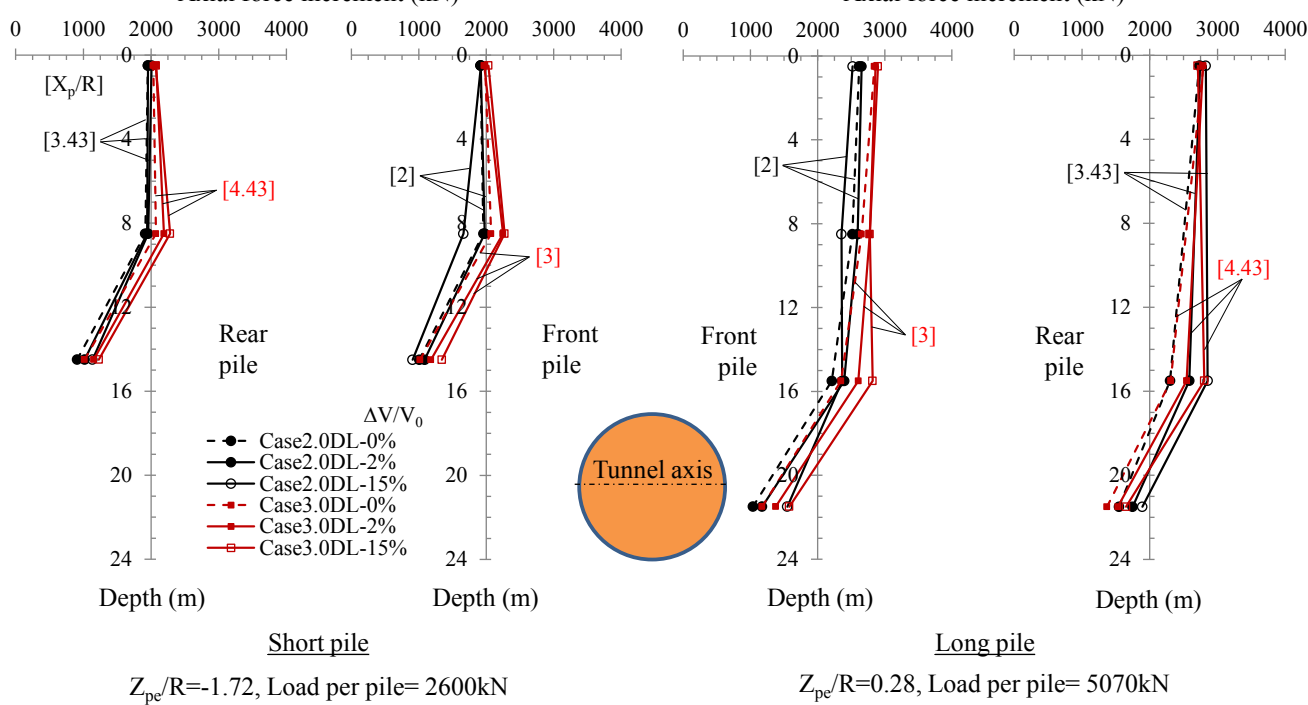

(b) $\mathrm{B}(2)$ series $(C / D=2.5)$

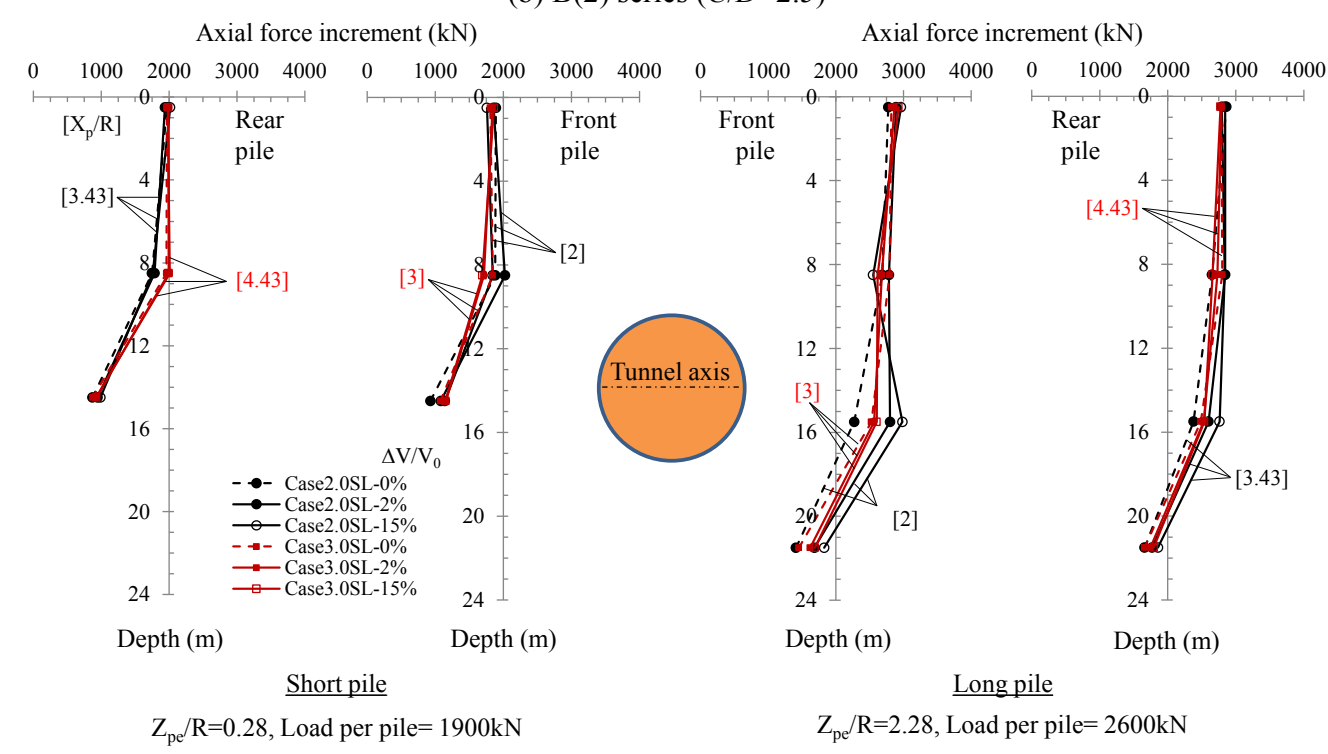

(c) $\mathrm{C}$ series $(C / D=1.5)$

Fig.14 Pile axial force increment profile with depth at ground loss ratio of $2 \%$ and $15 \%$. 


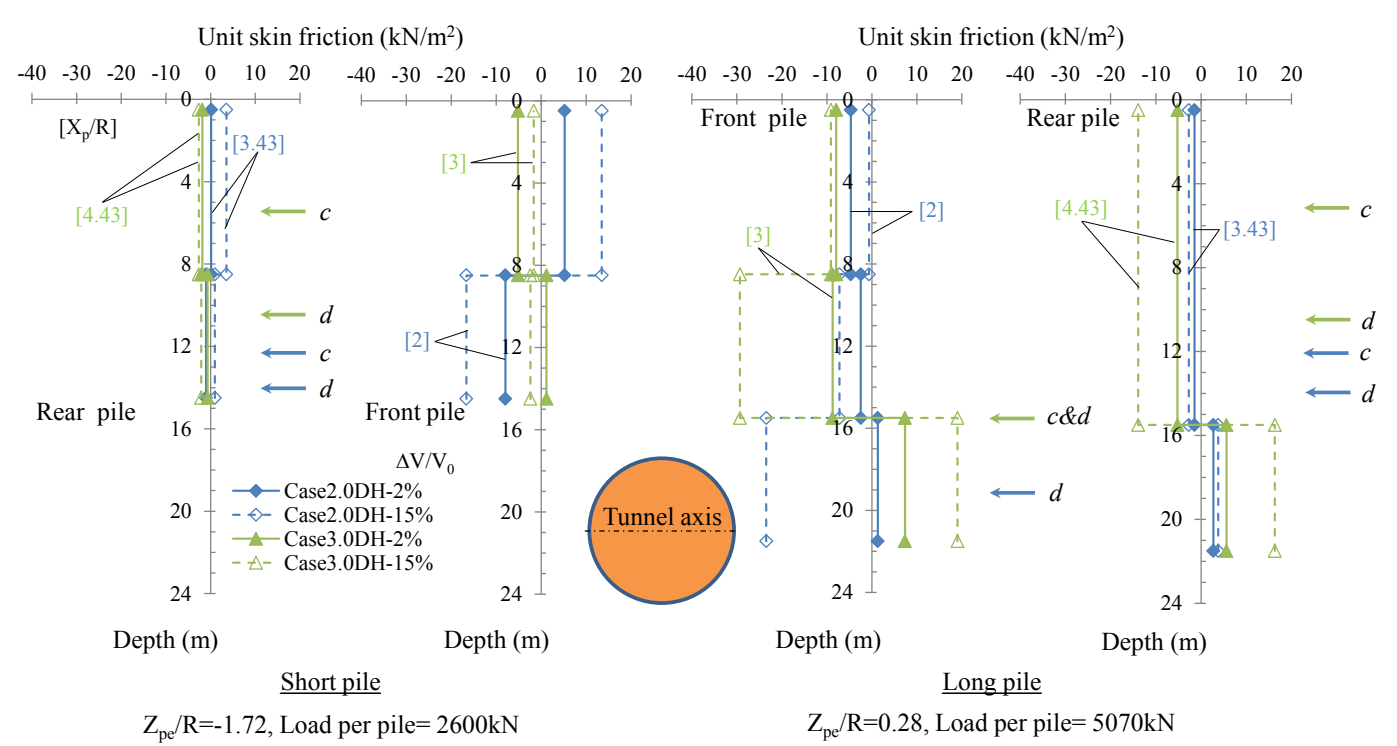

(a) $\mathrm{B}(1)$ series $(C / D=2.5)$

Unit skin friction $\left(\mathrm{kN} / \mathrm{m}^{2}\right)$

Unit skin friction $\left(\mathrm{kN} / \mathrm{m}^{2}\right)$

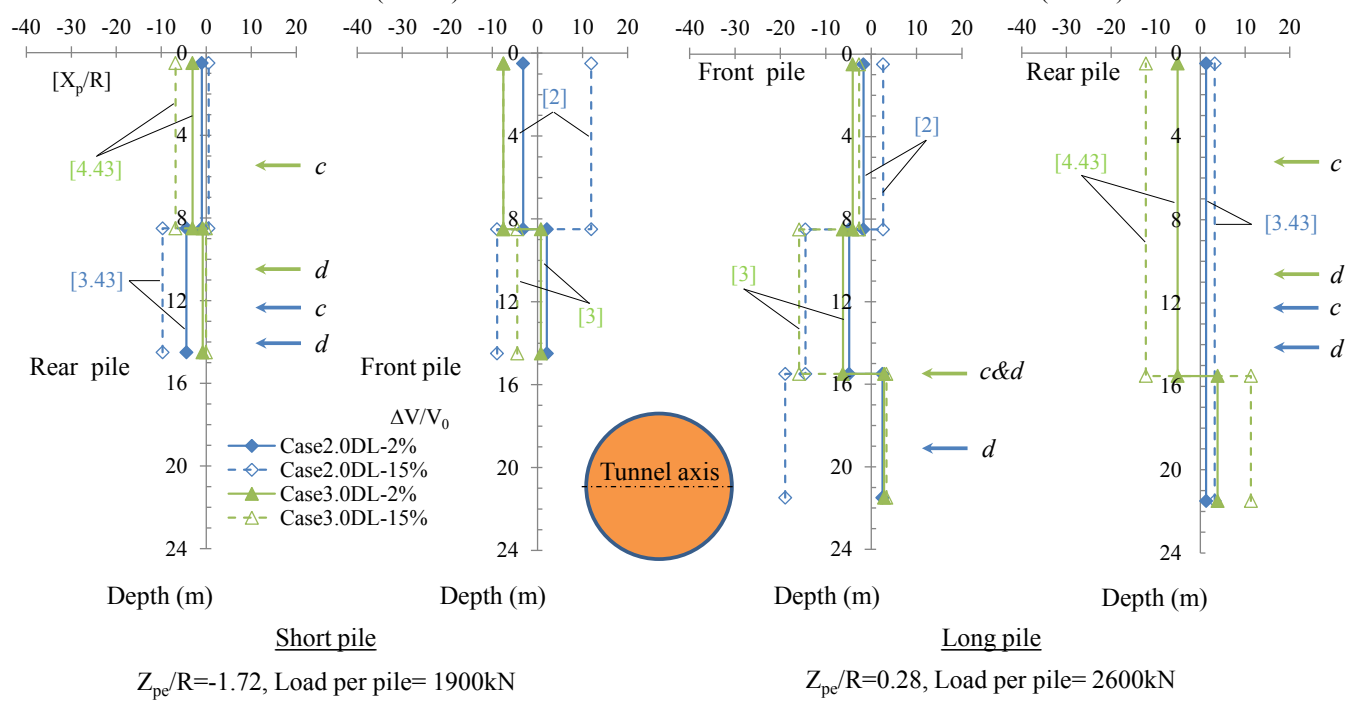

(b) $\mathrm{B}(2)$ series $(C / D=2.5)$

Unit skin friction $\left(\mathrm{kN} / \mathrm{m}^{2}\right)$

Unit skin friction $\left(\mathrm{kN} / \mathrm{m}^{2}\right)$

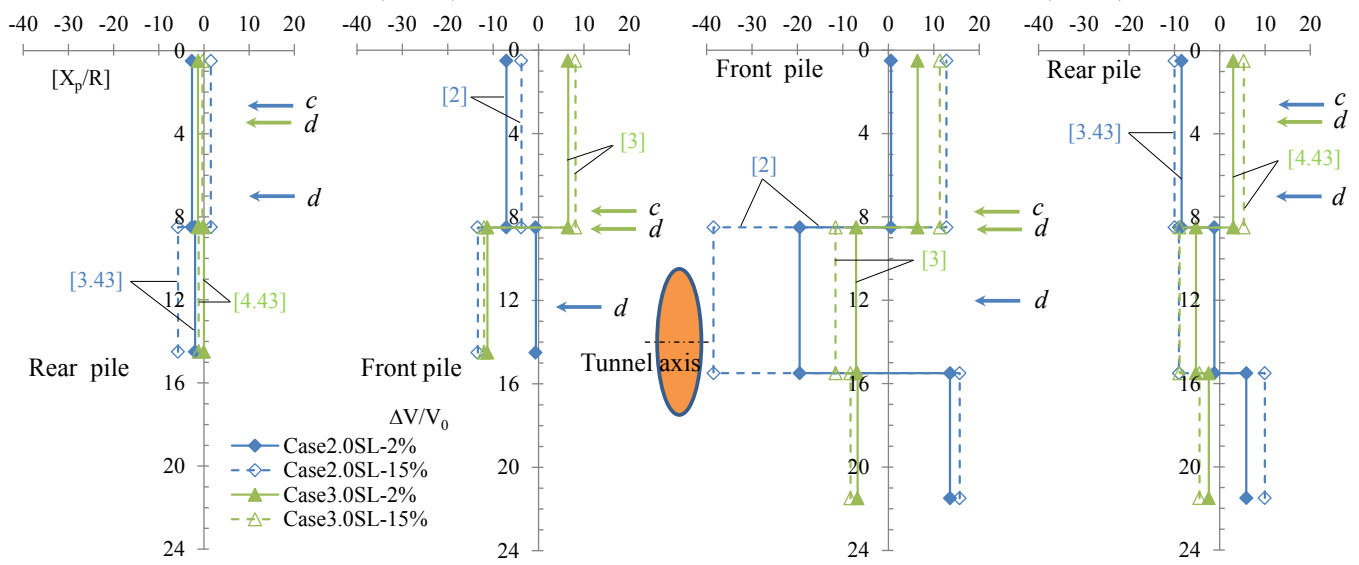

Depth (m) Depth (m)

Short pile

$\mathrm{Z}_{\mathrm{pe}} / \mathrm{R}=0.28$, Load per pile $=1900 \mathrm{kN}$

Depth (m)

Depth (m)

$\mathrm{Z}_{\mathrm{pe}} / \mathrm{R}=2.28$, Load per pile $=2600 \mathrm{kN}$

(c) $\mathrm{C}$ series $(C / D=1.5)$

Fig.15 Mobilization of pile skin frictions by tunneling at ground loss ratio of $2 \%$ and $15 \%$. 


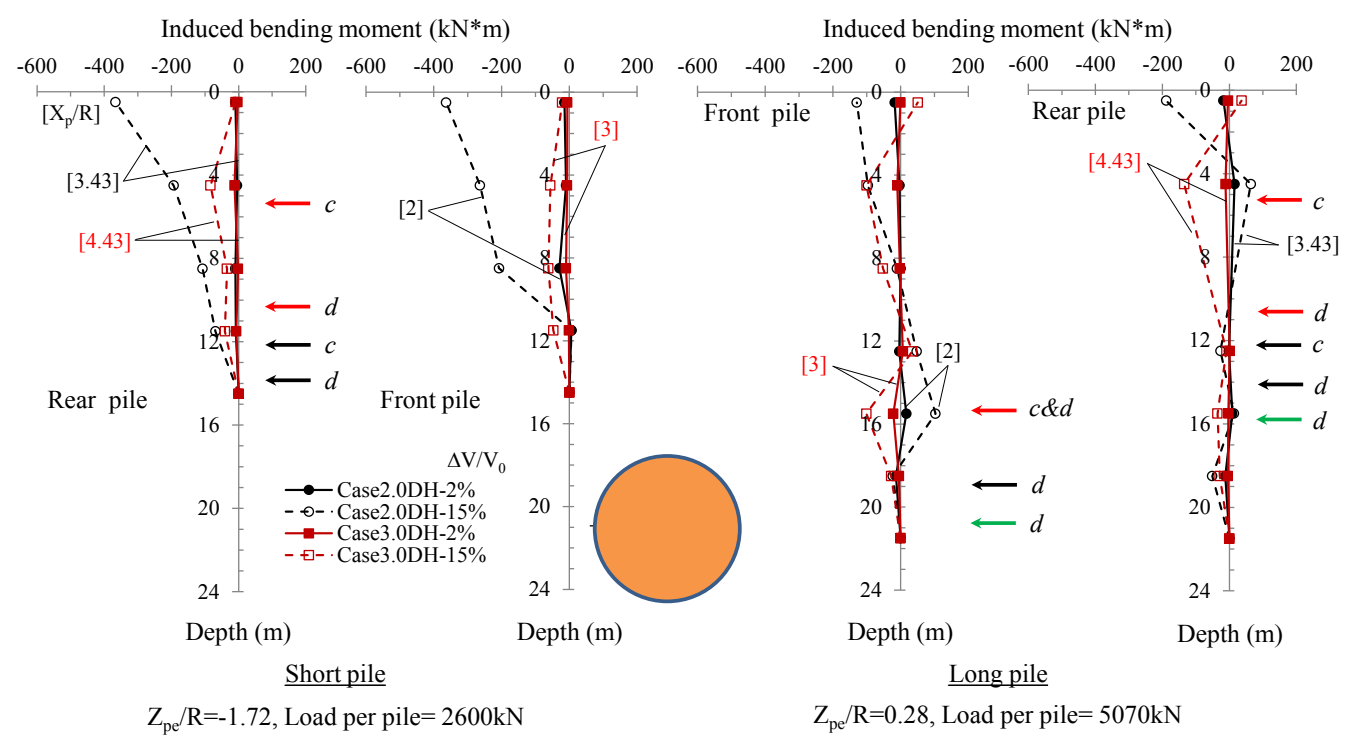

(a) $\mathrm{B}(1)$ series $(C / D=2.5)$

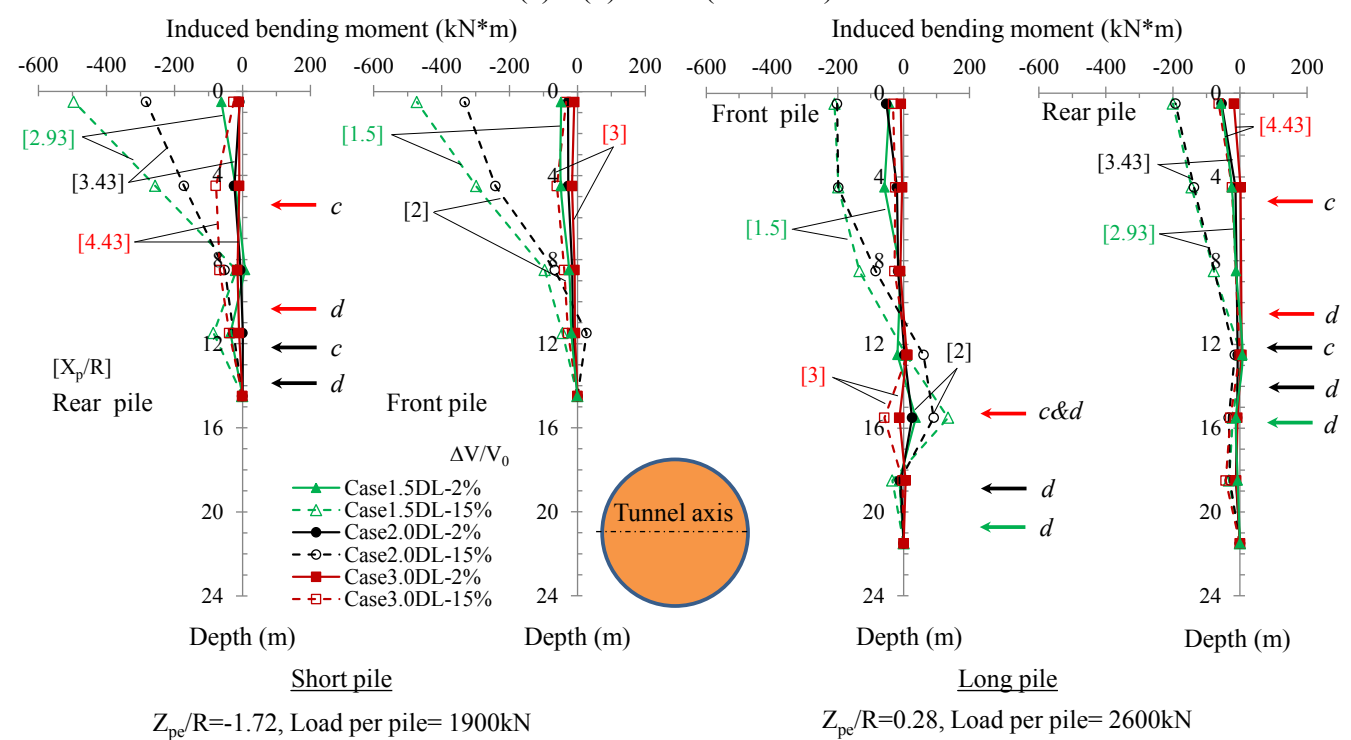

(b) $\mathrm{B}(2)$ series $(C / D=2.5)$

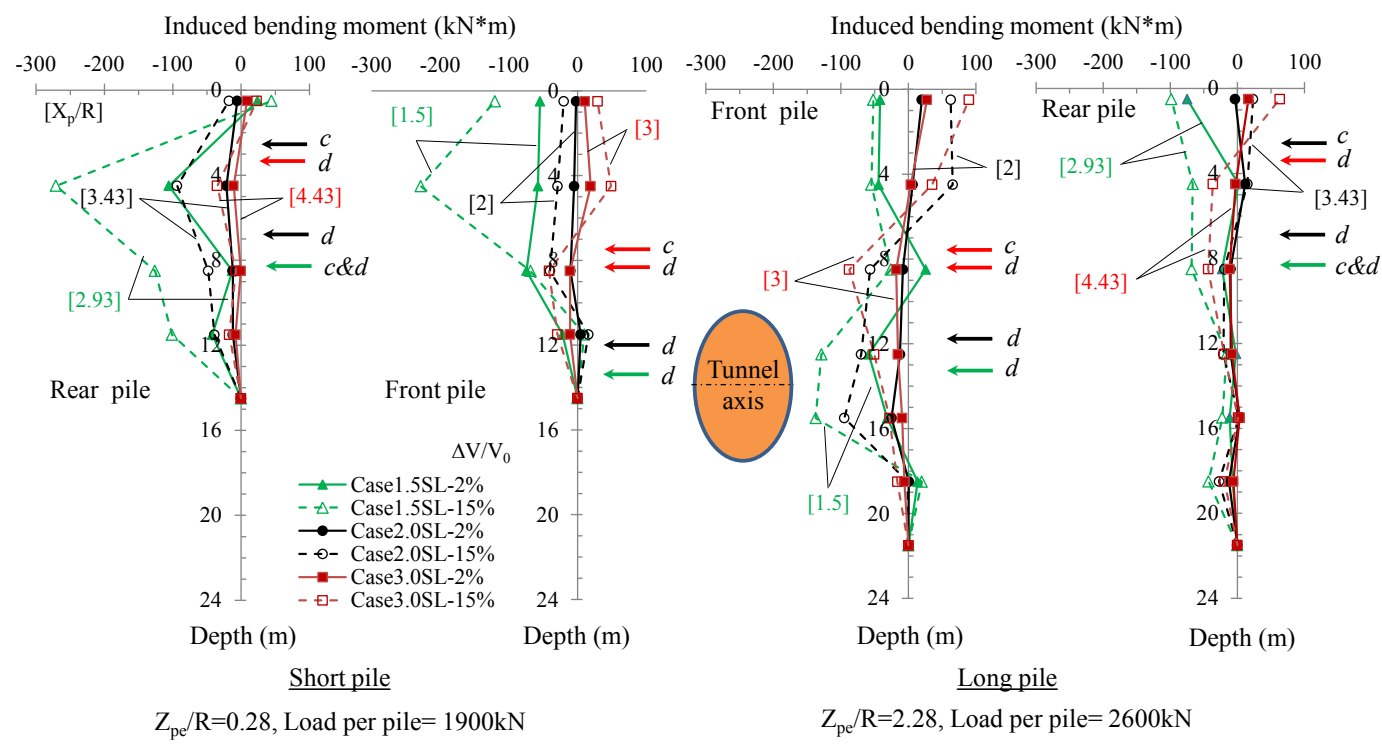

(c) $C$ series $(C / D=1.5)$

Fig.16 Pile bending moment profile with depth at ground loss ratio of $2 \%$ and $15 \%$. 
The displacements of the pile groups with the front piles at $X_{p}=3.0 R$ (Cases3.0DL and SL) were much smaller than those with the rear piles at $X_{p}=2.93 R$ (Cases1.5DL and SL). The effect of pile confinement in Zone D was also confirmed at the lower portion of the short pile in Case 1.5SL. The moments of the rear pile were larger for the rear pile than the front pile of which pile end was close to line d, the boundary of Zones $\mathrm{C}$ and $\mathrm{D}$.

From the above discussions, it can be said that the bending moment profile of the pile group is a result of complicated soil pile interaction, which is affected by many factors, such as ground loss, cover and depth ratio, horizontal pile location, pile depth, and the position (front and rear) of pile. Among the factors, the relative pile depth in the less displacement zone (Zone D) to the pile length $\left(Z_{d} / L\right)$ and the horizontal position $\left(X_{p}\right)$ are the critical controlling factors to the moment.

\section{(5) Applicability of $Z_{d a} / L$}

From the results in this study, the pile cap movements and the boundary of influence zone could be utilized to find the allowable ground loss among various relative positions between existing pile and new tunnel construction. The uneven settlement of structure, which can lead to additional and unexpected stresses on members and joints, becomes one of the important parameters to assess building stability.

The permissible inclination based on safety, functionality, and construction tolerances is proposed. ${ }^{27), 28)}$ Consequently, the recommended values for safety and affect stability of a building are equal to $0.003 \mathrm{rad}\left(\theta=0.17^{\circ}\right)$ and $0.005 \mathrm{rad}\left(\theta=0.29^{\circ}\right)$, respectively. The plot between development of inclination and ground loss is illustrated in Fig.17. The results were selected from test series $\mathrm{B}(2)$ and $\mathrm{C}$ with the same applied load from short and long pile groups. The values of $Z_{d a} / L, X_{p} / R$, and limited values of inclination for each case were indicated in the figure. As a result, the allowable ground loss for each pile group position could be estimated as indicated in Table 3. The allowable ground loss is one example to show the possible applicability of the proposed $Z_{d a} / L$ parameter. More researches should be conducted to improve the level of applicability of this method.

\section{CONCLUSIONS}

A series of centrifuge model tests was conducted to study the behavior of pile group subjected to tunnelling-induced soil movement. The model pile groups have four piles with square arrangement and five times pile diameter spacing.

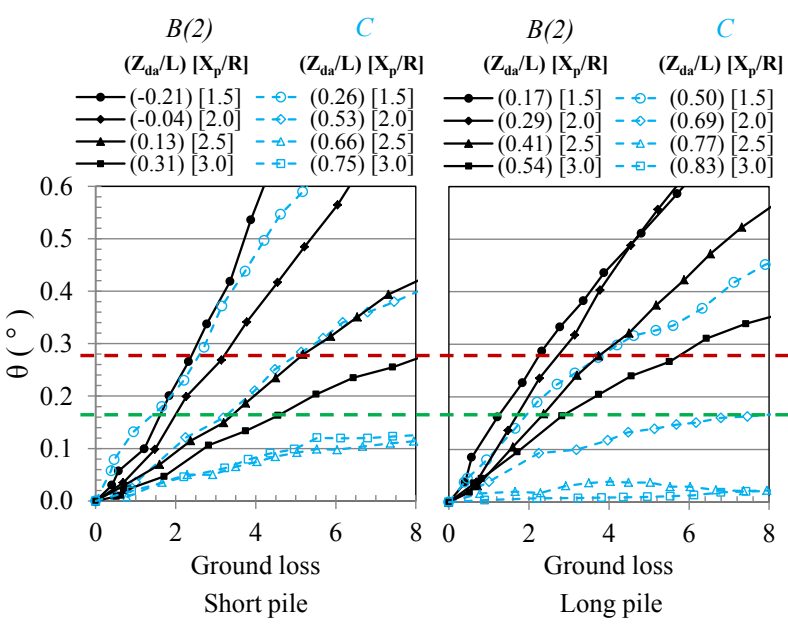

Fig.17 Pile cap inclination and ground loss with recommended range of inclination for building assessment.

Table 3 Allowable ground loss $\left(\Delta V / V_{0}, \%\right)$.

\begin{tabular}{|c|c|}
\hline Range of $Z_{d a} / L$ & Allowable ground loss (\%) \\
\hline$Z_{d a} / L<0.3$ & $2.0 \%$ \\
\hline $0.3 \leq Z_{d a} / L \leq 0.5$ & $3.0 \%$ \\
\hline $0.5 \leq Z_{d a} / L \leq 0.65$ & $4.0 \%$ \\
\hline$Z_{d a} / L>0.65$ & Negligible from tunneling \\
\hline
\end{tabular}

Two-dimensional tunneling-induced soil movement was introduced by using a mechanical machine, which can reduce the diameter with a fixed axis. The effects of tunnel cover depth, pile length, lateral position of piles from the tunnel, and vertical load to the pile group on the pile response were discussed. In the discussion, four zones of influence were defined referring to a previous study and observed subsoil deformation: Zones A and B were large soil movement zones above a tunnel, Zone $\mathrm{D}$ was a less-movement zone, and Zone $\mathrm{C}$ was a transient zone from Zone B to Zone D. From the study the following conclusions were drawn:

1. For small ground loss ratio $\left(\Delta V / V_{0}\right)$, the pile group movements increased almost proportionally to $\Delta V / V_{0}$. For the large $\Delta V / V_{0}$ over $3 \%$, the pile movement increment gradually decreased with $\Delta V / V_{0}$, except for the pile group with the front pile resting in the large displacement zone, the movement of which still proportionally increased with $\Delta V / V_{0}$.

2 . The behavior of pile group could be closely related to the zone of influence where the pile end rests and also the relative position of the pile end in the zone. In particular, the pile group experienced large lateral movement and inclination when the front and rear piles rested in or were close to Zone B and Zone $\mathrm{D}$, respectively. In other words, the front piles settled larger than the rear piles, causing a large uneven settlement. 
3. The pile depth in the less-movement zone $\left(Z_{d}\right)$ can be used as a parameter to approximate the effects of relative horizontal distance $\left(X_{p}\right)$ and relative positions between pile end and tunnel center $\left(Z_{p e}\right)$. It was found that when the relative depth from the zone to the pile length $\left(Z_{d a} / L\right)$ was larger, the effect from $X_{p}$ became small. In other words, the pile groups with large magnitude of $Z_{p e}$ showed small lateral movement and inclination of pile cap even though the front piles were close to the tunnel.

4. The measured axial force increased with increasing ground loss ratio for the piles resting in Zone D. For the pile resting in or close to Zone B, the end bearing load decreased during tunneling.

5. The pile resting in Zone D mostly developed negative skin friction at the pile shaft in Zones B and C due to the large soil movement relative to the piles, but positive skin friction was mobilized in Zone D.

6 . The bending moment profile of the pile group is a result of complicated soil pile interaction, which is affected by many factors, such as ground loss, cover and depth ratio, horizontal pile location, pile depth, and the position (front and rear) of pile. Among the factors, the relative pile depth in the less displacement zone (the Zone D) to the pile length $\left(Z_{d} / L\right)$ and the horizontal position $\left(X_{p}\right)$ are the critical controlling factors to the moment. The working loads slightly affected the increments of the bending moments and axial forces.

The ground loss caused by tunneling is likely to induce both vertical and lateral soil movements. These soil movements will cause some adverse effects on adjacent pile foundation, such as differential settlement between front and rear pile, reduction of end bearing in the zone of large soil movement, and induced additional axial force and bending moment. The pile groups tend to induce large magnitude of bending moment near the pile head due to pile cap rigidity.

The average of relative piles depth in the less movement zone $\left(Z_{d a} / L\right)$ could be used to estimate the allowable ground loss for assessment during preliminary design. However, in a practical situation, the final decision should be made by an experienced design engineer.

ACKNOWLEDGMENTS: The authors would like to acknowledge the research grant from the Centre of Urban Earthquake Engineering, and the Tokyo Institute of Technology for doing the experiments. The authors also appreciate the very kind support of Toyo Corporation, which provided the tunnel machine used in this study.

\section{REFERENCES}

1) Marshall, A. M., Farrell, R., Klar, A. and Mair, R. J.: Tun- nels in sands - the effect of size, depth, and volume loss on greenfield displacements, Geotechnique, Vol. 62, No. 5, pp. 385-399, 2012.

2) Lee, R. G., Turner, A. J. and Whitworth, L. J.: Deformations caused by tunneling beneath a piled structure, Proc. of 13th International Conference of Soil Mechanics and Foundation Engineering, Vol. 2, New Delhi, pp. 873-878, 1994.

3) Kaalberg, F. J., Teunissen, E. A. H., van Tol, A. F. and Bosch, J. W.: Dutch research on the impact of shield tunneling on pile foundations, Proc. of 16th International Conference of Soil Mechanics and Foundation Engineering, Vol. 3, Osaka, pp. 1615-1629, 2005.

4) Bezuijen, A. and Schrier, J. V.: The influence of a bore tunnel on pile foundations, Proc. of Centrifuge 94, pp. 681-686, 1994.

5) Nakai, T., Xu, L. and Yamazaki, H.: 3S and 2D model tests and numerical analyses of settlements and earth pressure due to tunnel excavation, Soils and Foundations, Vol. 37, No. 3, pp. 31-42, 1997.

6) Nakai, T. and Hinokio, M.: A simple elastoplastic model for normally and overconsolidated soils with unified material parameters, Soils and Foundations, Vol. 44, No. 2, pp. 53-70, 2004.

7) Sung, E., Shahin, H. M., Nakai, T., Hinokio, M. and Yamamoto, M.: Ground behavior due to tunnel excavation with existing foundation, Soils and Foundations, Vol. 46, No. 2, pp. 189-207, 2006.

8) Taylor, R. N.: Geotechnical Centrifuge Technology, London: Blackie Academic and Professional, 1995.

9) Lee, C. J. and Chiang, K. H.: Responses of single piles to tunneling-induced soil movements in sandy ground, Canadian Geotechnical Journal, Vol. 44, No. 10, pp. 1224-1241, 2007.

10) Loganathan, N., Poulos, H. G. and Stewart, D. P.: Centrifuge model testing of tunnelling-induced ground and pile deformations, Geotechnique, Vol. 50, No. 3, pp. 283-294, 2000 .

11) Takemura, J., Kondoh, M., Esaki, T., Kouda, M. and Kusakabe O.: Centrifuge model tests on double propped wall excavation in soft clay, Soils and Foundations, Vol. 39, No. 3, pp. 75-87, 1999.

12) Mair, R.: Centrifuge modelling of tunnel construction in soft clay, PhD. thesis, University of Cambridge, UK, 1979.

13) Katoh, Y., Miyake, M. and Wada, S.: Ground deformation around shield tunnel, Proceedings of the International Conference on Centrifuge Modelling (Centrifuge '98), Tokyo, Japan, 23-25 September 1998. Edited by T. Kimura, O. Kusakabe, and J. Takemura, Balkema, Rotterdam, the Netherlands, pp. 733-738, 1998.

14) Moh, Z. C., Hwang, R. N. and Ju, D. H.: Ground movements around tunnels in soft ground, Geotechnical Aspects of Underground Construction in Soft Ground (Mair, R. and Taylor, R. (eds.)), Balkema, Rotterdam, pp. 725-730, 1996.

15) White, D. J., Take, W. A. and Bolton, M. D.: Soil deformation measurement using particle image velocimetry (PIV) and photogrammetry, Geotechnique, Vol. 53, No. 7, pp. 619-631, 2003.

16) Boonsiri, I. and Takemura, J.: Behavior of pile group response to adjacent tunneling in sand using centrifuge modeling, Proc. of 8th International Conference of Physical Modelling in Geotechnics, The University of Western Australia, Australia, 14-17 January 2014, pp. 697-703, 2014.

17) Jacobsz, S. W., Standing, J. R., Mair, R. J., Hagiwara, T. and Sugiyama, T.: Centrifuge modelling of tunnelling near driven piles, Soils and Foundations, Vol. 44, No. 1, pp. 4956, 2004. 
18) Gui, M. W., Bolton, M. D., Garnier, J., Corte, J. F., Bagge, G., Laue, J. and Renzi, R.: Guidelines for cone penetration tests in sand, Proc. of the International Conference on Centrifuge Modelling (Centrifuge '98), Tokyo, Japan, 23-25 September 1998, Balkema, Rotterdam, the Netherlands, Vol. 1, pp. 155-160, 1998.

19) Ovensen, N. K.: Discussion on the use of physical models in design, Proc. 7th European Conference on Soil Mechanics and Foundation Engineering, Brighton 4, pp. 319-323, 1979.

20) Grant, R. J. and Taylor, R. N.: Centrifuge modeling of ground movements due to tunneling in layered ground, Geotechnical Aspects of Underground Construction in Soft Ground, Mair, R. and Taylor, R. (eds.), Balkema, Rotterdam, pp. 507-512, 1996.

21) Standing, J. R. and Leung, W. Y. M. T.: Investigating stresses around tunnels and piles using photo-elasticity techniques, Geotechnical Aspects of Underground Construction in Soft Ground, Taylor \& Francis Group, London, pp. 171-177, 2006.

22) Terzaghi, K.: Theoretical Soil Mechanics, John Wiley \& Sons, New York, 1943.

23) Lee, C. J., Chen, P. S., Chiang, K. H., Chen, H. T. and Lin, W. L.: Evolution of arching effect during tunneling in sandy soil, Physical Modelling in Geotechnics $6^{\text {th }} I C P M G^{\prime} 06, \mathrm{Ng}$,
Zhang and Wang (eds.), Taylor \& Francis Group, London, pp. 1171-1176, 2006.

24) Marshall, A. M., Farrell, R., Klar, A. and Mair, R. J.: Tunnels in sands - the effect of size, depth, and volume loss on greenfield displacements, Geotechnique, Vol. 62, No. 5, pp. 385-399, 2012.

25) Potts, R. B.: Behaviour of lined and unlined tunnels in sand, $\mathrm{PhD}$ Thesis, Engineering Department, Cambridge University, 1976.

26) Hergarden, H. J. A. M., van der Poel, J. T. and van der Schrier, J. S.: Ground movements due to tunnelling: Influence on pile foundations, Geotechnical Aspects of Underground Construction in Soft Ground (Mair, R. and Taylor, R. (eds.)), Balkema, Rotterdam, pp. 519-524, 1996.

27) McCormick, J., Aburano, H., Ikenaga, M. and Nakashima, M.: Permissible residual deformation levels for building structures considering both safety and human elements, The 14th World Conference on Earthquake Engineering, October 12-17, 2008, Beijing, China, 2008.

28) Kaga, K., Setou, M., Ochiai, A., Tsuzuki, T. and Ishikawa, F.: Vestibular sensitivity and sense of inclination, Japanese Journal of Cognitive Neuroscience, Vol. 7, No. 1, pp. 16-22, 2005 (In Japanese).

(Received March 28, 2014) 